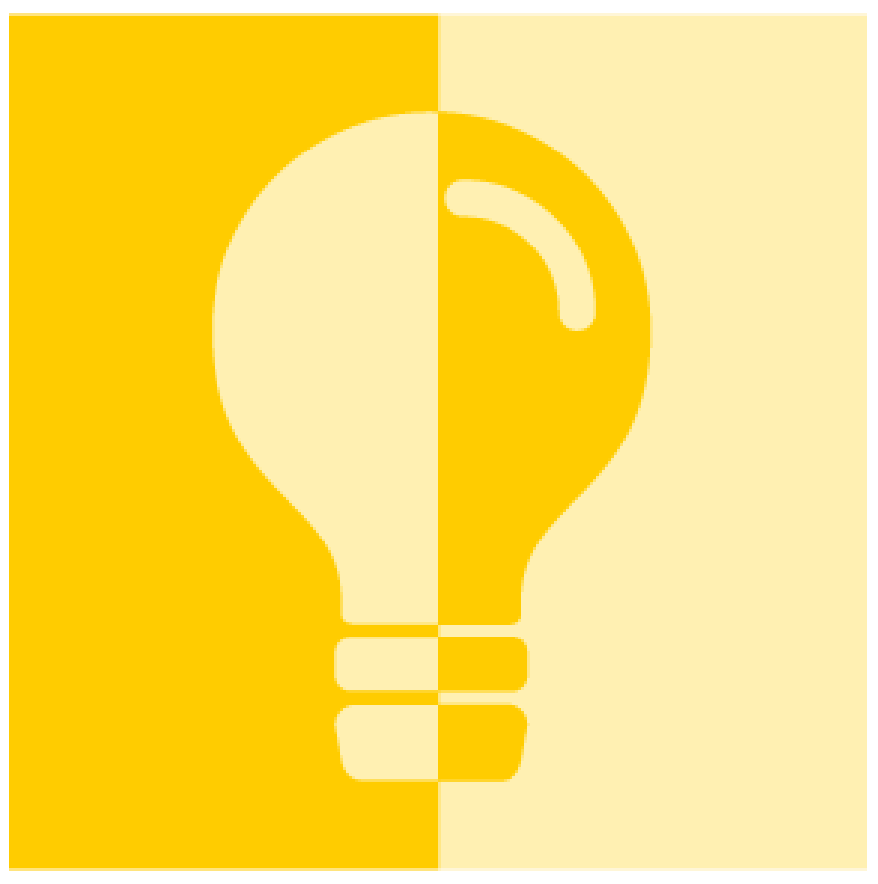

\title{
Energy Consumption Policies at the University of Michigan
}

\section{A Report Developed for and Supported by the \\ U-M President's Commission on Carbon Neutrality}

Revised July 31, 2020

\author{
Creators \\ Thomas Lyon, Faculty Lead \\ Jessica Carlin \\ Lyanda Dudley \\ Larson Lovdal \\ Taylor Lind \\ Katarina Nehrkorn
}

\section{Contributors}

Although he was not a formal part of the team, we owe a huge debt of gratitude to Kevin Morgan, Manager of the Energy Management program at U-M. Kevin has graciously shared internal data, spent countless hours working with our team, and provided insights that come from deep experience. This report would be much poorer without his contribution. 
Copyright (C) 2021 by the Regents of the University of Michigan

Some rights reserved

\section{(c) (i) $(9)$}

This work is licensed under the Creative Commons Attribution-NonCommercial-NoDerivatives 4.0 International License. To view a copy of this license, visit http://creativecommons.org/licenses/by-nc-nd/4.0/ or send a letter to Creative Commons, PO Box 1866, Mountain View, California, 94042, USA.

Published in the United States of America by Michigan Publishing

DOI: http://doi.org/10.3998/mpub.12094337

ISBN 978-1-60785-688-7 (open access)

This publication is a result of work sponsored by the University of Michigan (U-M) President's Commission on Carbon Neutrality (PCCN) to inform the PCCN's final recommendations to U-M President Mark Schlissel. This publication does not reflect Commission-level recommendations, and should not be interpreted as being recommendations of the PCCN nor carrying its endorsement. 


\section{CONTENTS}

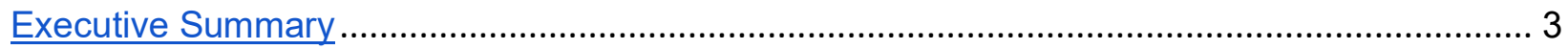

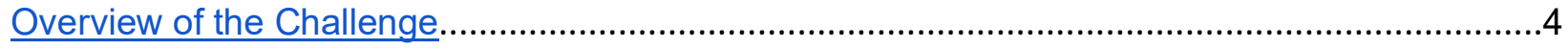

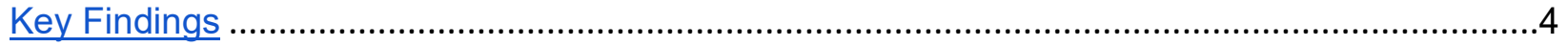

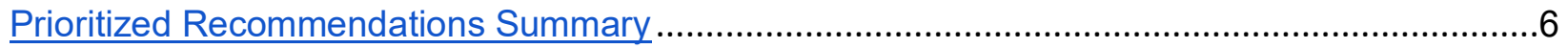

Priority \#1 Recommendation: Revolving Energy Fund .....................................................6

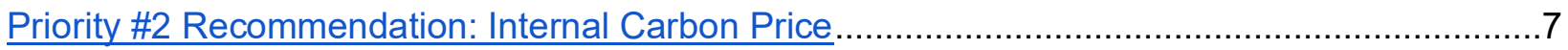

Priority \#3 Recommendation: Integration of REF and Carbon Pricing ..................................... 10

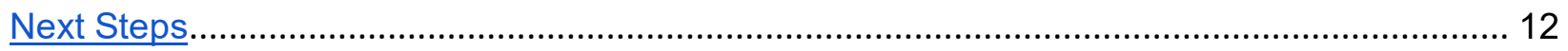

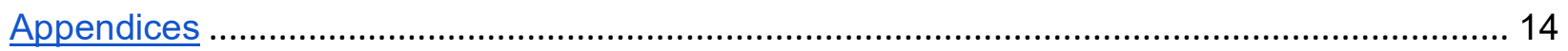

Appendix A: Peer Benchmarking........................................................................... 14

Appendix B: Analyses Based on GRITS Database ................................................. 16

Appendix C: University Baseline Emissions........................................................... 19

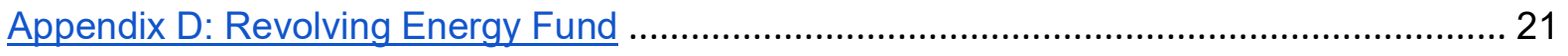

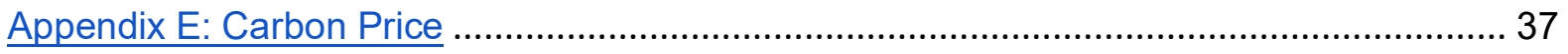

Appendix F: Details of Summary Table Calculations................................................. 40

Appendix G: Data on Flint and Dearborn Campuses................................................... 41

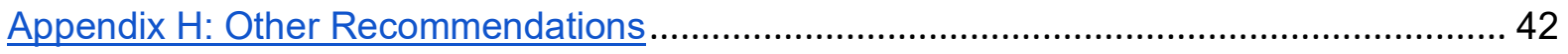

Appendix I: Internal and External Stakeholders ......................................................... 46

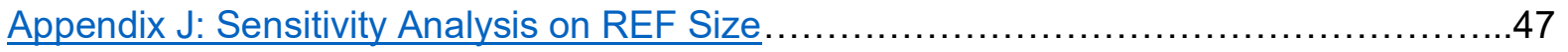

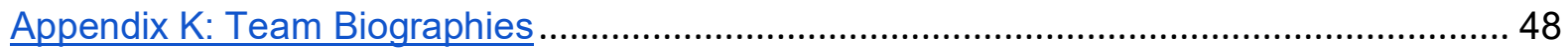

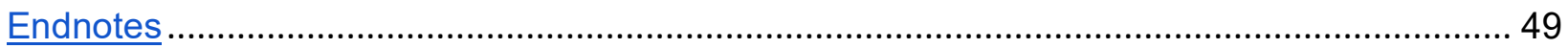




\section{EXECUTIVE SUMMARY}

Energy consumption is by far the largest source of carbon emissions at the University of Michigan (U-M). On the Ann Arbor campus, 98.5\% of energy use comes from buildings, so energy efficiency projects in existing buildings are a critical step toward carbon neutrality. They are also often good investments.

We propose to cut emissions from existing buildings by $25 \%$ over a 10 -year operating period from 2022 to 2031, for a reduction in annual emissions of roughly 105,000 metric tons $\mathrm{CO}_{2}$ equivalent $\left(\mathrm{MTCO}_{2} \mathrm{e}\right)$ by the start of 2032 and a cumulative reduction over the next decade of approximately 572,000 tons. This will require up-front investment, but the net present value to $\mathrm{U}-\mathrm{M}$ is estimated at $\$ 14.2$ million to $\$ 25.4$ million in only 10 years and $\$ 73$ million to $\$ 107$ million by 2050 . Thus, our proposals will actually save money for U-M while cutting emissions. Further emissions reductions appear possible as well, although they are likely to be more costly.

We propose two key policies: 1) a revolving energy fund (REF) and 2) an internal carbon price. The first would provide loans for business units to invest in energy conservation measures (ECMs). The second would provide a consistent price signal across business units commensurate with the external harms done by GHG emissions, provide incentives for greater energy efficiency, and generate funds for the REF. Because the policies are highly synergistic, our third recommendation is to implement them jointly, but one of them could potentially be adopted alone if that were somehow viewed to be optimal.

Priority 1 (REF): We propose a $\$ 24$ million REF to provide funds that can be borrowed by campus business units for investments in ECMs. As the loan is repaid out of the savings it generates, the funds can then be offered to other units, in a virtuous circle of improvements. We propose that initial seed funding for the REF come directly from the University, possibly from the endowment, as is done at many other schools. Revenues raised from carbon pricing-after subtracting out Direct Returns to units-would also go into the REF, and over time these funds could either be used to repay the initial seed funding or to accelerate U-M's investments in energy efficiency. Other universities of varying sizes (population, endowment/budgetary resources) have been able to sustain REFs over extended periods of time. We are confident that an REF would be an economically sound mechanism to support carbon neutrality at U-M.

Priority 2 (Carbon Price): We propose an internal carbon price based on the social cost of carbon, which is a monetary estimate of the damage done to human health and planetary ecosystems from a metric ton of greenhouse gas emissions. Estimates for the year 2020 range from as low as $\$ 22.60 / \mathrm{MTCO}_{2} \mathrm{e}$ to $\$ 266.50 / \mathrm{MTCO}_{2} \mathrm{e} .{ }^{1}$ As a baseline, we use the value of $\$ 50 / \mathrm{MTCO}_{2} \mathrm{e}$ offered by the Interagency Working Group.

Carbon prices at this level will amount to less than $0.25 \%$ of the overall U-M budget, so addressing carbon neutrality should not be prohibitively expensive. Nevertheless, we propose to phase in implementation of the plan over five years to not "shock the system." Year 1 will involve only a "proxy carbon price" to help building managers understand how a financially binding carbon price will affect their operations and their budgets. The full carbon price would be gradually phased in from Year 2 to Year 5.

We would return $30 \%$ of the revenues from the carbon price directly back to individual business units, based on a five-year rolling average of the unit's historic energy consumption. This Direct Return funding will be earmarked for investment in projects that will help increase the unit's energy efficiency, such as metering and hiring energy managers. 


\section{FINAL REPORT}

\section{Overview of the Challenge}

Energy use is by far the largest source of U-M's carbon emissions. Our team's task was to devise policies to help reduce our energy consumption and hence our carbon emissions. On the Ann Arbor campus, $98.5 \%$ of energy use comes from buildings, so reducing our carbon footprint through energy efficiency projects in existing buildings is a crucial step toward carbon neutrality. Although U-M has been making progress in reducing its energy intensity, this has been constrained by inadequate incentives and inadequate funding for energy conservation measures. Our proposals ameliorate both of these problems.

\section{Key Findings}

As detailed in Appendix A, many other universities already have REFs. The Billion Dollar Green Challenge lists 58 institutions with a total of $\$ 122$ million committed to REFs. ${ }^{2}$ Harvard created an REF of $\$ 12$ million in 2002, which produces roughly $\$ 4$ million/year in energy savings. Carbon pricing is less common. Yale, Swarthmore, and Smith have experimented with an internal carbon price, but this idea has not diffused as widely as the REF concept. This is an area where our proposals may offer an example that might be followed by other schools.

U-M has made progress on energy efficiency, but this varies across units. General Fund units on campus have made meaningful progress, due largely to the efforts of a dedicated team of energy managers led by Kevin Morgan. Auxiliary units (e.g., Athletics, NCRC, the U-M Health System, the Student Unions) have a great amount of autonomy and have not been part of the General Fund's energy management program. However, U-M Health has invested in an energy manager on its own and made significant energy efficiency investments.

We have excellent data on the performance of energy conservation measures (ECMs) installed in General Fund units over the past 13 years, which are incorporated into the GRITS database. These ECMs have been limited to relatively small-scale projects, however, due to the fact that campus-wide capital investments in energy efficiency are currently only $\$ 1.2$ million/year. GRITS data on these investments suggest that the average cost of abatement has been $-\$ 35.98 /$ ton and that the median return on investment $(\mathrm{ROI})$ has been $22.67 \%{ }^{3}$ This means that GHG reductions from ECMs actually make money for U-M. These outstanding financial results suggest that we are significantly underinvesting in ECMs. Moreover, based on the GRITS data, there is no sign that we have picked all the "low-hanging fruit," as the ROI of projects in GRITS shows no sign of decreasing over time. (See Appendix B for details on the GRITS database and our financial calculations.)

Because of the aforementioned budget constraints, the University has not invested significantly in "deep retrofits" of existing buildings. Hence, we lack good data on which to base estimates of the potential for deep retrofits to reduce emissions in a cost-effective fashion. This has been perhaps the single greatest impediment to our ability to provide a precise, reliable estimate of what can be accomplished with our proposed policies. We believe it is reasonable to apply historical ECM results to the future up to at least the point where we achieve a $25 \%$ reduction in emissions from existing $U-M$ buildings, but the cost of abatement may increase beyond that point. This is consistent with our finding that the ROI on ECMs internally has held steady over the last 13 years. It is also roughly in line with the $25 \%$ reduction commitment made by Engie to the Ohio State University. Beyond the 25\% level, we expect that the cost of abatement may increase, and we explore possible options below. We take as a baseline a $30 \%$ annual increase in the cost of achieving an additional ton after the $25 \%$ reduction. 


\section{Equity Concerns}

In terms of intra-campus equity, units differ substantially in the amount of carbon pollution they emit, the energy efficiency of the buildings in which they operate, and the financial resources they have available. This creates the potential for a variety of concerns about equity. Equity is an important issue, since it is the fundamental rationale for the "polluter pays principle": put simply, it is fundamentally inequitable for polluters to impose damages on others as a result of their own emissions. In essence, carbon polluters have been receiving a carbon subsidy because they have not been required to pay for the harm they do to others. The larger the pollution from a given unit, and the longer that unit has been given a "free ride" to pollute, the larger the total carbon subsidy that unit has received. Units with low levels of carbon emissions might well argue that other units with large emissions should be required to contribute to carbon neutrality not just based on their current emissions levels but also in proportion to the historical carbon subsidy they have received.

We do not go so far as to propose that campus units be required to pay for the historical damages they have imposed on the planet. We do propose that each unit should be required to pay for the damages they are currently imposing. This view is not radical and is in fact widely shared. Over 3,500 economists have endorsed carbon pricing, including 27 Nobel Laureates and all of the living former Chairs of the Federal Reserve (https://www.historyismade.org/). On July 29, 2020, over 350 Student Government Presidents from around the country, including University of Michigan, announced their support for carbon pricing (see https://www.s4cd.org).

We doubt many individuals at U-M question the importance of climate action or support subsidizing pollution. Nevertheless, it is human nature to search for reasons why others should shoulder the burden of taking action and to couch those reasons in the language of fairness. "It is not fair for us to pay, because other units have more money." "It is not fair for us to pay, because the work we do is so valuable and requires a lot of energy." "It is not fair for us to pay, because we already invested in energy efficiency." "It is not fair for us to pay, because it would be hard for us to reduce emissions."

In our view, the ethical force behind the polluter pays principle is overwhelming. It is consistent with the Golden Rule, Kant's categorical imperative, and the fundamental principles of tort law. At the same time, we are very sympathetic to the legitimate concerns of campus units with budgets stretched tight by COVID-19 and other challenges. Thus, we have included three key features in our proposal that are designed to alleviate these concerns. First, we phase in a carbon price slowly over five years so that units can adjust to the new system and take early action to reduce their emissions and associated carbon payments. Second, we include a $30 \%$ Direct Return of a unit's carbon payments back to the unit to fund reductions in carbon emissions and future carbon payments. The amount of Direct Return funds will thus be proportionate to a unit's emissions, so that high-emitting units receive more Direct Return funds. Third, the REF we propose will provide equitable access to capital. We expect that units with fewer resources are likely to have made less progress on energy efficiency, to have greater opportunities for efficiency improvements, and hence to obtain a disproportionate share of funds from the REF, so that lower-resource units receive more REF funds.

As we understand it, budgets for the various $U-M$ campuses are entirely decentralized, which makes it impossible for the Ann Arbor campus to fund ECMs on the Flint and Dearborn campuses. Moreover, data on energy use and GHG emissions for individual buildings on these two campuses are very poor, because energy costs are paid centrally. As a result, we have been unable to develop detailed analyses of policies for these two campuses. 


\section{Carbon Footprint and Accounting}

The Office of Campus Sustainability (OCS) reports that in FY2019, total campus energy use was 6,924,524 MMBtu, and building energy use was 6,822,849 MMBtu, or $98.5 \%$ of the total. Energy supply is primarily a mix of cogenerated steam and electricity powered by natural gas combustion on campus (4,957,588 MCF, responsible for 278,190 $\left.\mathrm{MTCO}_{2} \mathrm{e}\right)$, combined with electricity purchased from DTE Energy $\left(530,862 \mathrm{MWh}\right.$, responsible for $\left.365,184 \mathrm{MTCO}_{2} \mathrm{e}\right)$. Total campus $\mathrm{GHG}$ emissions were $645,485 \mathrm{MTCO}_{2} \mathrm{e}$, of which buildings were responsible for $98.5 \%$, or $636,007 \mathrm{MTCO}_{2} \mathrm{e}$.

However, the baseline level of emissions for U-M will soon drop substantially as a result of two major steps. First, $U-M$ is expanding its on-campus generation capability, which will replace some purchased electricity from DTE with power from a gas-fired combustion turbine, with a lower emissions factor than DTE power in the short-to-medium run. It is expected to reduce our emissions by approximately $62,000 \mathrm{MTCO}_{2} \mathrm{e}$ in 2021. Second, U-M is signing a Power Purchase Agreement (PPA) with DTE Energy for 200,000 MWh/year, ${ }^{4}$ which is expected to reduce GHG emissions in 2022 by $107,598 \mathrm{MTCO}_{2} \mathrm{e}$. Together, these important steps will cut U-M baseline emissions to roughly 414,000 $\mathrm{MTCO}_{2} \mathrm{e}$ in 2022. As DTE's grid becomes cleaner over the following 10-year period, this baseline will continue to decline (see Appendix $\mathrm{C}$ for a detailed analysis).

\section{Prioritized Recommendations Summary}

We recommend two key actions: 1) create a revolving energy fund (REF) and 2) implement carbon pricing on campus. We believe that either action separately could in principle deliver on our goal of a $25 \%$ reduction of GHG emissions from existing buildings by the year 2031 . However, we also believe that the combination of the two policies produces synergies that will lead to faster GHG reductions, more favorable and more equitable economic outcomes, and a more rapid transformation of campus attitudes and culture around carbon neutrality. Hence Priority \#3 is to combine them.

\section{Priority \#1 Recommendation: Revolving Energy Fund}

Description of recommendation. An REF is a well-established financial mechanism for funding energy conservation and carbon reduction projects at large institutions and cities across the United States. U-M business units ${ }^{5}$ will submit project proposals to the REF with quantified energy and financial savings. If approved, the REF provides the unit with a loan to cover the upfront capital expense, which is repaid to the fund through utility bill savings from lower energy consumption.

Carbon emissions reduction potential. As stated above, the REF is expected to reduce University emissions by $25 \%$ through energy conservation projects. By the end of 10 years, annual emissions will be 104,727 $\mathrm{MTCO}_{2}$ e lower than at the start of 2022. Over this same period, this would reduce cumulative U-M emissions by approximately $572,238 \mathrm{MTCO}_{2} \mathrm{e}$. Valued at a social cost of $\$ 50 / \mathrm{MTCO}_{2} \mathrm{e}$, this reduction would contribute about $\$ 28.6$ million to global welfare.

Financial costs and savings. With a current capital investment budget of $\$ 1.2$ million and a budget of $\$ 1.7$ million for staff salaries and benefits, the current OCS Energy Management Team reduces U-M carbon emissions by an additional 1,700 $\mathrm{MTCO}_{2} \mathrm{e}$ each year in General 
Fund buildings. With a far greater budget and inclusion of non-General Fund units, the University could achieve a much higher level of abatement with an REF. Due to incomplete information on the energy reduction potential of buildings on campus, especially for deep retrofits, we based our abatement goals on Engie's guaranteed energy use intensity (EUI) reduction for the Ohio State University of $25 \%$ over 10 years. ${ }^{6,7}$ Implementing this goal at U-M will require a $\$ 24$ million REF, funding both ECM projects and the labor costs of energy management staff who identify and propose projects. These additional labor costs will include roughly a quadrupling of the current energy management staff. See Appendix D.8 for the seed funding derivation and Appendix D.9 for staffing justification.

Operations. We defer to Appendix D as a full description of our proposal for the detailed operation of the REF, which incorporates concerns regarding achieving reductions at the lowest possible cost, procedural fairness, and equity across U-M business units. The following people are required for successful implementation of the REF: Leads, Assistants, Regional Energy Managers (REMs), a Technical Committee (TC), a Selection Committee (SC), and a Rollout Committee. See Appendix D.2 for detailed descriptions of each role.

\section{Priority \#2 Recommendation: Internal Carbon Price}

Climate change is rapidly transforming our planet and demands urgent action. Yet one of society's most powerful guiding forces-economics-remains underutilized in addressing the crisis, because those who emit greenhouse gases are not required to pay for the damages they cause. Carbon pricing addresses this misalignment by internalizing emissions' impacts into economic decisions through a price on greenhouse gases. International, national, and subnational units have recognized the value of appropriate economic signaling through carbon pricing, including leading higher education institutions such as Yale, which has a $\$ 40 / \mathrm{MTCO}_{2} \mathrm{e}$ internal carbon price. ${ }^{8}$ Implementing a carbon price at U-M would create the incentives and the means for decision makers to drive toward carbon neutrality by reducing energy consumption and $\mathrm{CO}_{2}$ emissions.

Internal carbon pricing refers to a carbon price within an organization such as a company or university. In the absence of external emissions pricing systems, internal pricing is an opportunity to 1) demonstrate meaningful environmental commitment and leadership, 2) cost-effectively reduce energy and emissions, and 3) implement a customized pricing system to match organizational structure and goals. The proposed pricing system is designed to capitalize on each of these categories while fitting smoothly into existing organizational structures and maintaining the University's core mission.

Figure 1 shows the proposed internal carbon pricing system. Business units are charged according to their carbon footprint, which is tracked and billed through the existing utilities billing system. The revenue is divided into two portions, one portion $(30 \%)$ of which is returned directly to the contributing unit, earmarked for efficiency initiatives, and the remainder of which is contributed to the REF described previously in this proposal. (If the Commission rejects the REF, the remaining funds could be directed to the existing OCS Energy Management Team.) The Direct Return revenue is calculated using a five-year moving average of emissions to reduce annual uncertainty and maintain strong reduction incentives. This revenue portion captures the benefits of distributed investment, giving units the capacity for active energy management such as paying energy management staff, performing building audits to identify efficiency opportunities, and investing in small conservation projects. This revenue stream will not be sufficient for large capital projects. The carbon charge would begin at $\$ 50 / \mathrm{MTCO}_{2} \mathrm{e}$ based on the social cost of carbon and escalate at $2.5 \%$ per year. To further incentivize action by units, the top two units by percentage emissions reduction each year would receive an 
additional $10 \%$ of their carbon charge revenue. The desire for a competitive component was a clear lesson from Yale's pilots with different pricing systems.

To administer the carbon price on the Ann Arbor campus, we recommend using the existing utilities billing system for building energy consumption. The utilities department has confirmed the technical feasibility of adding carbon emissions and associated charges, and OCS already tracks greenhouse gas data by business unit. In addition, U-M can use the existing GRITS software to track project-by-project results of carbon pricing. (Although not shown in the figure, we also propose in coordination with the University Travel Internal Analysis Team to apply the carbon price to all flights for University purposes, which generate roughly 50,000 $\mathrm{MTCO}_{2} \mathrm{e} /$ year. Yale Divinity School uses a flat fee of $\$ 50 /$ domestic flight and $\$ 100 /$ international flight, but we propose to use a sliding scale based on distance traveled, which would be more educational for travelers. This fee could be implemented through the Concur system U-M uses for travel reimbursement.) In sum, the technical implementation of an internal carbon price is quite feasible.

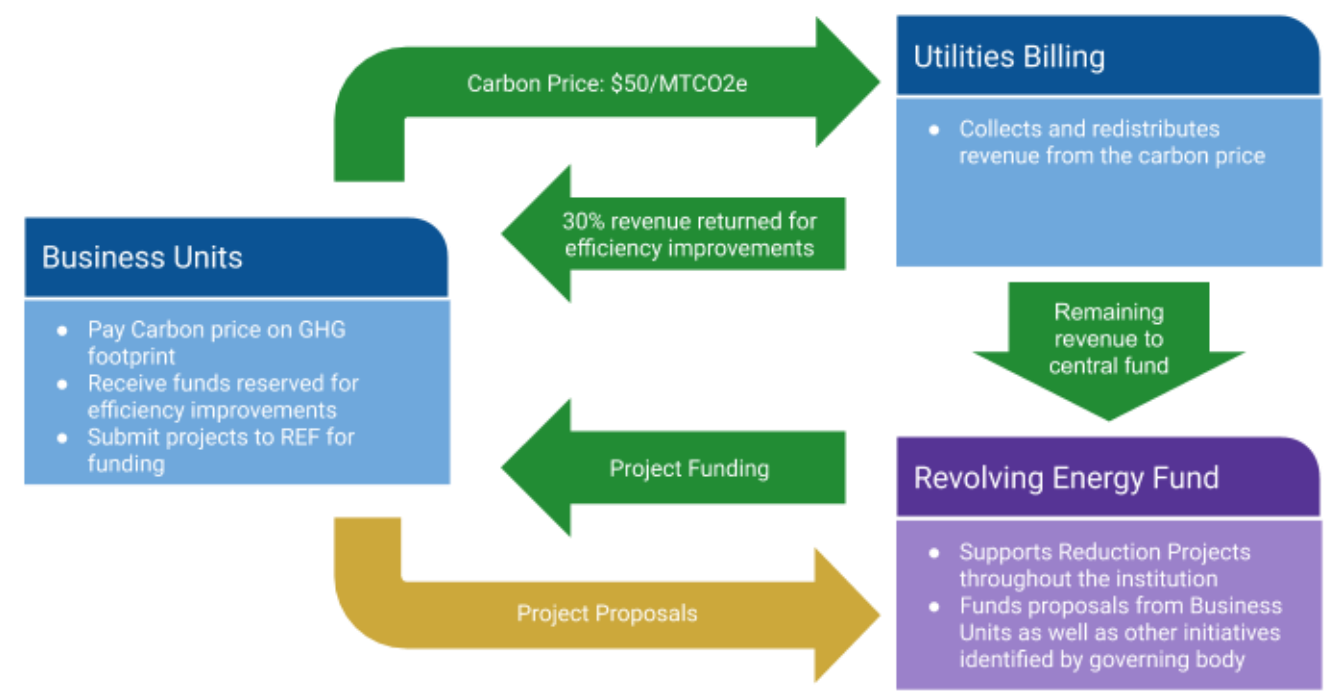

Figure 1. Internal Carbon Pricing Structure for the University of Michigan

Financial implications. To assess the efficacy and financial implications of the proposed system, we spoke with the Provost's office, Utilities division, and CFOs/facility managers of twelve General Fund and auxiliary business units as well as representatives from the Dearborn and Flint campuses. Throughout these conversations, stakeholders emphasized the need to introduce carbon pricing without causing a financial shock. In response, we recommend a fiveyear implementation schedule as shown in Table 1 with an informational (no money collected) "proxy price" in Year 1, 25\% of the target price in Year 2, 50\% in Year 3, and so forth, reaching the target price in Year 5. The phase-in period gives units critical time to develop administrative infrastructure, expand capacity (staff, expertise, data) for active energy management, and budget appropriately before being fully financially affected. We received positive feedback from the Provost's office on the concept of a phase-in over several years, though the exact timeline may require adjustment due to changing financial circumstances and/or budget pressures. The carbon price should include a "built-in" update process, such as a three- or five-year review, during which a predetermined group reviews the policy structure to ensure it still efficiently incentivizes the desired outcomes.

Table 1 summarizes the implications of carbon pricing for $\mathrm{U}-\mathrm{M}$, including emissions, costs, emissions reductions, and relative budgetary impact through 2031 . The relative budget impact is $0.20 \%$ or less even for the fully implemented escalating carbon price. Considering the 
General Fund's 10 -year growth rate of $4.7 \%$, even this small percentage is likely overstated. To further quantify the financial impacts of a carbon price, we calculate the cost for each business unit on the Ann Arbor campus in Appendix E. There we examine three scenarios with $30 \%$, $40 \%$, and $50 \%$ Direct Return of funds, but we focus on the $30 \%$ scenario. We also show the percentage impact on units' overall annual budgets. In general, budget impacts are well below $1 \%$, with only three units above $1 \%$. Internal carbon pricing is an opportunity to align U-M business units and broader administrative interests around decarbonizing the University's energy supply. Because even the most efficient buildings use some energy and U-M controls energy purchasing centrally, swift central action toward decarbonization is the quickest way to reduce the carbon price burden across all units.

\begin{tabular}{|c|c|c|c|c|c|c|c|c|c|c|c|}
\hline & 2021 & 2022 & 2023 & 2024 & 2025 & 2026 & 2027 & 2028 & 2029 & 2030 & 2031 \\
\hline Price (\$/MTCO2) & $\$ 0.00$ & $\$ 12.50$ & $\$ 25.00$ & $\$ 37.50$ & $\$ 50.00$ & $\$ 51.25$ & $\$ 52.53$ & $\$ 53.84$ & $\$ 55.19$ & $\$ 56.57$ & $\$ 57.98$ \\
\hline Emissions (MTCO2) & 558,801 & 412,146 & 398,246 & 381,754 & 362,535 & 334,166 & 304,785 & 267,110 & 235,894 & 197,065 & 177,130 \\
\hline Total Cost & $\$ 0.00 \mathrm{M}$ & $\$ 6.99 \mathrm{M}$ & $\$ 10.30 \mathrm{M}$ & $\$ 14.93 \mathrm{M}$ & $\$ 19.09 \mathrm{M}$ & $\$ 18.58 \mathrm{M}$ & $\$ 17.55 \mathrm{M}$ & $\$ 16.41 \mathrm{M}$ & $\$ 14.74 \mathrm{M}$ & $\$ 13.34 \mathrm{M}$ & $\$ 11.43 \mathrm{M}$ \\
\hline Direct Return Revenue & $\$ 0.00 \mathrm{M}$ & $\$ 2.10 \mathrm{M}$ & $\$ 3.09 \mathrm{M}$ & $\$ 4.48 \mathrm{M}$ & $\$ 5.73 \mathrm{M}$ & $\$ 5.57 \mathrm{M}$ & $\$ 5.27 \mathrm{M}$ & $\$ 4.92 \mathrm{M}$ & $\$ 4.42 \mathrm{M}$ & $\$ 4.00 \mathrm{M}$ & $\$ 3.43 \mathrm{M}$ \\
\hline Revenue to REF & $\$ 0.00 \mathrm{M}$ & $\$ 4.89 \mathrm{M}$ & $\$ 7.21 \mathrm{M}$ & $\$ 10.45 \mathrm{M}$ & $\$ 13.36 \mathrm{M}$ & $\$ 13.01 \mathrm{M}$ & $\$ 12.29 \mathrm{M}$ & $\$ 11.49 \mathrm{M}$ & $\$ 10.32 \mathrm{M}$ & $\$ 9.34 \mathrm{M}$ & $\$ 8.00 \mathrm{M}$ \\
\hline Percent of Operating Budget & $0.00 \%$ & $0.07 \%$ & $0.11 \%$ & $0.16 \%$ & $0.20 \%$ & $0.19 \%$ & $0.18 \%$ & $0.17 \%$ & $0.15 \%$ & $0.14 \%$ & $0.12 \%$ \\
\hline
\end{tabular}

Table 1. Carbon price implementation schedule and budget impacts through 2031 for the Ann Arbor campus. Assumes a constant U-M operating budget of $\$ 9.6$ billion based on 2019 levels.

Ultimately, internal carbon pricing works twice for the University, providing a price signal as well as investment funding. The pricing system outlined above is specifically designed to incentivize action as well as provide the means for material progress toward carbon neutrality without placing undue stress on the systems that allow U-M to deliver on its core mission.

Emissions potential. The proposed carbon price would include primarily scopes 1 and 2 emissions, which are already tracked uniformly across business units on the Ann Arbor campus. (Consistent with the recommendations of the University Travel Internal Analysis Team, we propose applying the carbon price to all University air travel as well. Other emissions sources could be readily incorporated once consistent tracking is established.) One approach to estimating the potential carbon emissions reduction due to a carbon price is to utilize long-run price elasticity of demand estimates for each energy source, as shown in Appendix E. To account for "stickiness," or the phase-in time for the full long-run elasticity to be realized, we used 10 years as a reasonable estimate for how long it would take for critical infrastructure to be replaced. Using 2019 University of Michigan consumption and price data coupled with elasticity data from Washington State Department of Commerce's Carbon Tax Assessment Model ${ }^{9}$ and the U.S. Energy Administration Association, ${ }^{10}$ we estimated the reduction in consumption over 10 years assuming a $\$ 50 / \mathrm{MTCO}_{2} \mathrm{e}$ price. These calculations estimate a $139,106 \mathrm{MTCO}_{2} \mathrm{e}$ reduction by 2032 . This approach assumes that only normal market forces are at work, with no acceleration of reductions from using carbon revenues to fund internal reductions. It thus almost certainly underestimates what is possible. We also estimate the emissions reductions using the historic cost of abatement per ton from GRITS, a software tool that tracks energy efficiency projects at U-M. (We assume historic costs per ton can be maintained out to a $25 \%$ reduction in emissions but that costs per ton rise at a rate of $30 \%$ per year after that.) For this method, we assume the total revenue from the carbon price is spent on reducing emissions either via the $30 \%$ Direct Return funding or through a central fund. The estimated abatement with this method is a $210,129 \mathrm{MTCO}_{2}$ e baseline reduction (51\% reduction) by 2032 and a cumulative abatement of $\sim 943,000 \mathrm{MTCO}_{2} \mathrm{e}$ over 10 years. The GRITS data generally represent quite favorable 
projects (in terms of ROI and cost of abatement), although as pointed out earlier, there is no shortage of such projects, and we have assumed the marginal cost of abatement increases sharply after a $25 \%$ reduction is achieved. The elasticity estimates assume U-M cannot implement change faster than the broader economy. In this way, the estimates offer approximate upper and lower bounds on the potential abatement; we suspect the GRITS method is more accurate since it is based on detailed local data, and it is what is represented in Table 2 below. For a detailed explanation of the calculations, see Appendix E. We also provide spreadsheet tools with which to explore alternative assumptions on the marginal cost of abatement.

Equity and justice. Consideration needs to be given to interdepartmental differences among the Ann Arbor campus building units. Initially, more efficient buildings will have the advantage of paying less because they have a lower energy use intensity compared to less efficient buildings. However, less efficient buildings will receive a larger amount of direct return funds and, in principle, will have more competitive projects for consideration by the central energy efficiency fund. This system attempts to capture both distributed and centralized energy investment benefits as fairly as possible.

Broader impacts. Additionally, after analyzing various carbon pricing tools, we found that the Direct Return funds earmarked for energy efficiency projects would be a novel and equitable incentive structure. U-M could pilot this feature so that peer universities could learn about the transferability of a carbon price to a large-scale public institution. Implementing this recommendation would be a major contribution to the existing body of knowledge on carbon pricing and a step toward leadership in higher education climate action. Strong leadership will be a deciding factor in the success or failure of carbon pricing at U-M.

\section{Priority \#3 Recommendation: Integration of REF and Carbon Pricing}

The REF and carbon price both play important roles in providing the incentive and means for reducing emissions through energy conservation projects. The Summary Table (Table 2) outlines how emissions are reduced, and the cost of reduction is incurred differently by adopting the REF, the carbon price, or both. The underlying assumptions in this table are the following: 1) it is realistic to reduce emissions by $25 \%$ within 10 years at the same historic cost of abatement using either or a combination of our recommendations ${ }^{11}$; 2) beyond a $25 \%$ reduction, the cost of abatement rises sharply, at a rate of $30 \%$ per year; and 3) the "all in" cost to cut the flow of emissions by an additional ton (including labor costs such as the salaries and benefits of energy managers and the capital costs of ECMs) is $\$ 914 / \mathrm{MTCO}_{2} \mathrm{e} .{ }^{12}$ The "Snapshot Impact" column in the table summarizes the main points of each scenario.

The REF allows U-M to begin investing more in ECMs in the near term, which generates long-term benefits in terms of total abatement and net financial benefits. As shown in panel 1 of Table 2, a \$24 million REF alone can achieve a 25\% reduction in emissions in 10 years with a financial net present value (NPV) of $\$ 25.4$ million. The carbon price sends valuable price signals that incentivize units to cut energy use and also provides funding in later years for ECMs.

However, because the carbon price is phased in slowly over the first five years of operation, it is slower to begin generating returns from efficiency improvements and hence does not generate the same financial performance as the REF. As shown in panel 2 of Table 2, a carbon price of $\$ 50 /$ ton alone (with no seed funding for an REF) can potentially achieve even greater abatement over 10 years $(50 \%)$ but at a lower NPV of \$-22.7 million. (Note that this is only accounting for the first 10 years of savings and thus understates the long-run financial benefits of the carbon price.) The lower NPV is a direct result of phasing in the carbon price slowly over 
five years, delaying the funding and installation of valuable energy savings even as it provides greater funding in the later years of the policy. The two measures can be combined in many different possible ways, depending upon U-M willingness to provide initial seed funding for the REF and to impose a carbon price equal to the social cost of carbon. By varying the mix, U-M can achieve a higher NPV, greater abatement, or both.

\begin{tabular}{|c|c|c|c|c|c|c|c|c|c|c|c|c|c|}
\hline SNAPSHOT IMPACT & & 2021 & 2022 & 2023 & 2024 & 2025 & 2026 & 2027 & 2028 & 2029 & 2030 & 2031 & TOTAL \\
\hline \multicolumn{14}{|c|}{ HIGH REF SEED FUNDING + NO CARBON PRICE } \\
\hline REF Seed Funding: $\$ 24 \mathrm{M}$ & Incremental Emissions Reduced & 0 & 10,341 & 15,313 & 6,747 & 7,947 & 9,850 & 11,055 & 10,573 & 10,477 & 10,892 & 11,534 & 104,730 \\
\hline Carbon Price: \$0/MTCO2 & Total Reduction Below Baseline & 0 & 10,341 & 25,655 & 32,401 & 40,349 & 50,199 & 61,254 & 71,827 & 82,304 & 93,196 & 104,730 & \\
\hline Emissions Reduction: $\mathbf{2 5 \%}$ & Annual Costs & $\$ 24.0 \mathrm{M}$ & $\$ 0.0 \mathrm{M}$ & $\$ 0.0 \mathrm{M}$ & $\$ 0.0 \mathrm{M}$ & $\$ 0.0 \mathrm{M}$ & $\$ 0.0 \mathrm{M}$ & $\$ 0.0 \mathrm{M}$ & $\$ 0.0 \mathrm{M}$ & $\$ 0.0 \mathrm{M}$ & $\$ 0.0 \mathrm{M}$ & $\$ 0.0 \mathrm{M}$ & $\$ 24.0 \mathrm{M}$ \\
\hline \multirow[t]{2}{*}{ NPV: $\$ 25.4 \mathrm{M}$} & Annual Savings & $\$ 0.0 \mathrm{M}$ & $\$ 1.4 \mathrm{M}$ & $\$ 3.4 \mathrm{M}$ & $\$ 4.3 \mathrm{M}$ & $\$ 5.3 \mathrm{M}$ & $\$ 6.6 \mathrm{M}$ & $\$ 8.1 \mathrm{M}$ & $\$ 9.5 \mathrm{M}$ & $\$ 10.9 \mathrm{M}$ & $\$ 12.3 \mathrm{M}$ & $\$ 13.8 \mathrm{M}$ & $\$ 75.5 \mathrm{M}$ \\
\hline & $\%$ Reduction Below Baseline & $0.00 \%$ & $2.50 \%$ & $6.19 \%$ & $7.82 \%$ & $9.74 \%$ & $12.12 \%$ & $14.78 \%$ & $17.34 \%$ & $19.87 \%$ & $22.49 \%$ & $25.28 \%$ & $25.28 \%$ \\
\hline \multicolumn{14}{|c|}{ NO REF SEED FUNDING + MODERATE CARBON PRICE } \\
\hline REF Seed Funding: $\$ 0 M$ & Incremental Emissions Reduced & 0 & 2,167 & 8,147 & 13,064 & 19,748 & 25,825 & 30,237 & 34,433 & 29,827 & 25,402 & 21,304 & 210,154 \\
\hline Carbon Price: $\$ 50.00 / \mathrm{MTCO} 2$ & Total Reduction Below Baseline & 0 & 2,167 & 10,314 & 23,378 & 43,127 & 68,951 & 99,188 & 133,621 & 163,448 & 188,850 & 210,154 & \\
\hline Emissions Reduction: $\mathbf{5 1 \%}$ & Annual Cost & $\$ 0.0 \mathrm{M}$ & $\$ 7.0 \mathrm{M}$ & $\$ 10.3 \mathrm{M}$ & $\$ 14.9 \mathrm{M}$ & $\$ 19.1 \mathrm{M}$ & $\$ 18.6 \mathrm{M}$ & $\$ 17.6 \mathrm{M}$ & $\$ 16.4 \mathrm{M}$ & $\$ 14.7 \mathrm{M}$ & $\$ 13.3 \mathrm{M}$ & $\$ 11.4 \mathrm{M}$ & $\$ 143.4 \mathrm{M}$ \\
\hline \multirow{2}{*}{ NPV: $-\$ 22.7 \mathrm{M}$} & Annual Savings & $\$ 0.0 \mathrm{M}$ & $\$ 0.3 \mathrm{M}$ & $\$ 1.4 \mathrm{M}$ & $\$ 3.1 \mathrm{M}$ & $\$ 5.7 \mathrm{M}$ & $\$ 9.1 \mathrm{M}$ & $\$ 13.1 \mathrm{M}$ & $\$ 17.6 \mathrm{M}$ & $\$ 21.6 \mathrm{M}$ & $\$ 24.9 \mathrm{M}$ & $\$ 27.7 \mathrm{M}$ & $\$ 124.5 \mathrm{M}$ \\
\hline & \% Reduction Below Baseline & $0.00 \%$ & $0.52 \%$ & $2.49 \%$ & $5.64 \%$ & $10.41 \%$ & $16.64 \%$ & $23.94 \%$ & $32.25 \%$ & $39.45 \%$ & $45.58 \%$ & $50.72 \%$ & $50.72 \%$ \\
\hline \multicolumn{14}{|c|}{ MODERATE REF SEED FUNDING + LOW CARBON PRICE } \\
\hline REF Seed Funding: $\$ 16 \mathrm{M}$ & Incremental Emissions Reduced & 0 & 10,601 & 8,601 & 5,932 & 7,875 & 10,016 & 11,125 & 11,386 & 12,369 & 13,282 & 14,525 & 105,711 \\
\hline Carbon Price: \$6.00/MTCO2 & Total Reduction Below Baseline & 0 & 10,601 & 19,203 & 25,134 & 33,009 & 43,025 & 54,150 & 65,536 & 77,904 & 91,186 & 105,711 & \\
\hline Emissions Reduction: $\mathbf{2 6 \%}$ & Annual Cost & $\$ 16.0 \mathrm{M}$ & $\$ 0.8 \mathrm{M}$ & $\$ 1.2 \mathrm{M}$ & $\$ 1.8 \mathrm{M}$ & $\$ 2.4 \mathrm{M}$ & $\$ 2.4 \mathrm{M}$ & $\$ 2.5 \mathrm{M}$ & $\$ 2.5 \mathrm{M}$ & $\$ 2.6 \mathrm{M}$ & $\$ 2.6 \mathrm{M}$ & $\$ 2.6 \mathrm{M}$ & $\$ 37.5 \mathrm{M}$ \\
\hline \multirow[t]{2}{*}{ NPV: \$14.2M } & Annual Savings & $\$ 0.0 \mathrm{M}$ & $\$ 1.4 \mathrm{M}$ & $\$ 2.5 \mathrm{M}$ & $\$ 3.3 \mathrm{M}$ & $\$ 4.4 \mathrm{M}$ & $\$ 5.7 \mathrm{M}$ & $\$ 7.1 \mathrm{M}$ & $\$ 8.6 \mathrm{M}$ & $\$ 10.3 \mathrm{M}$ & $\$ 12.0 \mathrm{M}$ & $\$ 14.0 \mathrm{M}$ & $\$ 69.3 \mathrm{M}$ \\
\hline & $\%$ Reduction Below Baseline & $0.00 \%$ & $2.56 \%$ & $4.63 \%$ & $6.07 \%$ & $7.97 \%$ & $10.38 \%$ & $13.07 \%$ & $15.82 \%$ & $18.80 \%$ & $22.01 \%$ & $25.51 \%$ & $25.51 \%$ \\
\hline
\end{tabular}

Table 2. Summary Table for Different Scenarios

In the combined scenario, implementation of the REF will precede the carbon price to lessen the initial financial burden on business units. This will give them a chance to organize and/or implement energy efficiency projects with funds from the REF and reduce their emissions before being charged for them. The revenue generated from the carbon price and earmarked for energy efficiency will increase, giving more back to units. Once the carbon price reaches full implementation in 2025, the funds returned to units will grow large enough to, in theory, offset the annual cost of energy management staff incurred with the implementation of an REF (which, as described above, is estimated to be $\$ 6.8 \mathrm{M})$. This contributes to the reduction in total cost in the combined scenario by using carbon price revenues to both grow the REF and supplement the cost of its operation.

One version of a combined REF and carbon price is presented in panel 3 of the Summary Table and is calibrated to produce an abatement level equivalent to that produced in panel 1 by the REF alone. The combination of the two policies allows for achievement of a $25 \%$ reduction with seed funding for the REF of only $\$ 16$ million and with a carbon price of only $\$ 6 /$ ton. Many other combinations of policies are possible, and we are leaving the Commission with a spreadsheet tool that allows for exploration of any desired scenario. For example, suppose U-M prefers to set a carbon price equal to the social cost of carbon, which sends appropriate price signals to units regarding the damages their emissions create. The University could create a sizable REF with seed funding and use revenues from the carbon price in later years to pay itself back for the up-front investment. Many other options are also possible.

The two policies work well together because they incentivize increased use of each mechanism more than if only one were implemented. Without the carbon price, use of the REF for energy efficiency projects would be less urgent to units; without the REF, the carbon price would be placing a larger financial burden on units before centralized revenues grow large enough to begin funding energy efficiency projects for all units to reduce their emissions.

The NPV values in Table 2 reflect only costs and savings incurred during the period from 2021 through 2031. If one looks out all the way to 2050 , the flows of energy and financial savings will continue to accrue based on the investments made over the next decade. This, in turn, will make estimates of the NPV from energy efficiency much larger and the cost per ton of carbon abated much lower. Table 3 presents our summary results from this longer-term 
perspective, assuming that the level of abatement and energy savings achieved in 2031 continue to exist through the year 2050 and assuming no new investments in ECMs after 2031. All three policy options now register very large and positive NPV values. Cumulative lifetime emissions reductions range from 2.5 million tons to 4.9 million tons. The cost of abatement shown in the table is simply the NPV divided by lifetime emissions reductions, and because the NPV of each policy option is positive, the COA number must be interpreted as showing that the cost of abatement is negative and ranges from $-\$ 14.83 /$ ton to $-\$ 41.60 /$ ton. The bottom line is that energy efficiency cuts carbon emissions and generates a financial benefit to U-M.

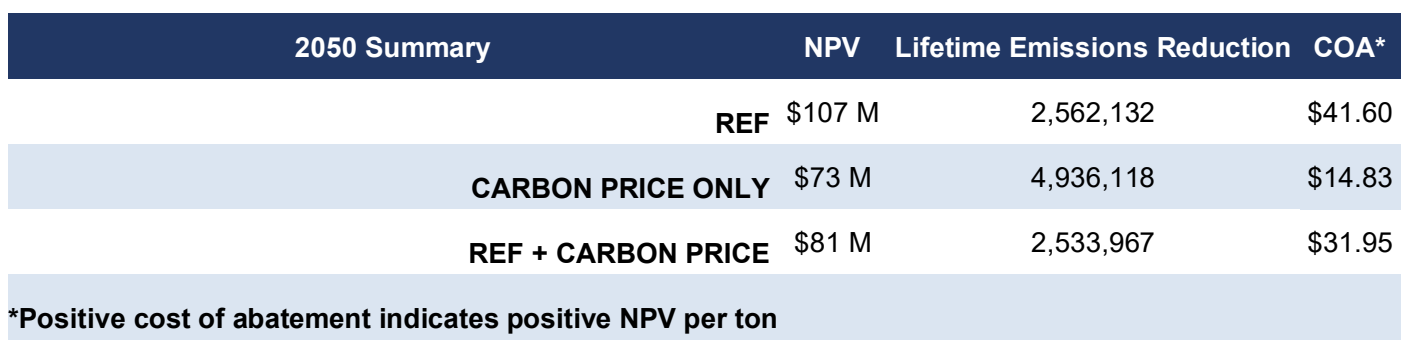

Table 3. Summary Results Evaluated Out to 2050 (NPV in 2020\$)

The tables presented here focus only on the Ann Arbor campus, due to data limitations. We recognize there are significant differences in resources and needs across the three U-M campuses, and after speaking with representatives from both Flint and Dearborn, it is clear that under their current budget structures and data constraints, a carbon price as described above does not fit their context. The current University structure also does not allow transferring of resources between campuses, so Flint, Dearborn, and Ann Arbor cannot be incorporated into a single system of either carbon pricing or REF funding. From available utilities data for FY2019, we can project the total cost of a fully phased-in carbon price for these campuses at $\$ 1.14$ million for Dearborn and \$1.35 million for Flint. Similar to the earmarked carbon price revenue, this can be viewed as a lower benchmark for an annual sustainability budget. Furthermore, approximate seed funding needs for REFs at each institution are estimated to be $\$ 2.2$ million for Dearborn and \$2.4 million for Flint. ${ }^{13}$ We strongly recommend that Flint and Dearborn are actively engaged in crafting the PCCN's final recommendations to ensure they are appropriate and relevant. At a minimum, we recommend hiring at least one energy management staff member at each campus and establishing individual REFs.

\section{NEXT STEPS}

Implementation of our proposals to reduce energy consumption will require strong central support. The most critical near-term action items for U-M to catalyze progress on this topic are illustrated in the timeline in Figure 2.

A first priority is to begin communicating broadly with the campus community about the culture changes needed around carbon pricing and energy efficiency. It is necessary that units and individuals have a clear understanding of why U-M is taking this important step, with clear expectations of the benefits to the University and the broader society, and the reasoning behind the new policies. This will be especially important for the carbon price, as it will place a modest amount of pressure on campus budgets. The U-M administration must publicly commit to a timeline for implementing these policies in order for stakeholders to have confidence that carbon neutrality is being taken seriously and for the University to be able to hold itself accountable for its commitments. 


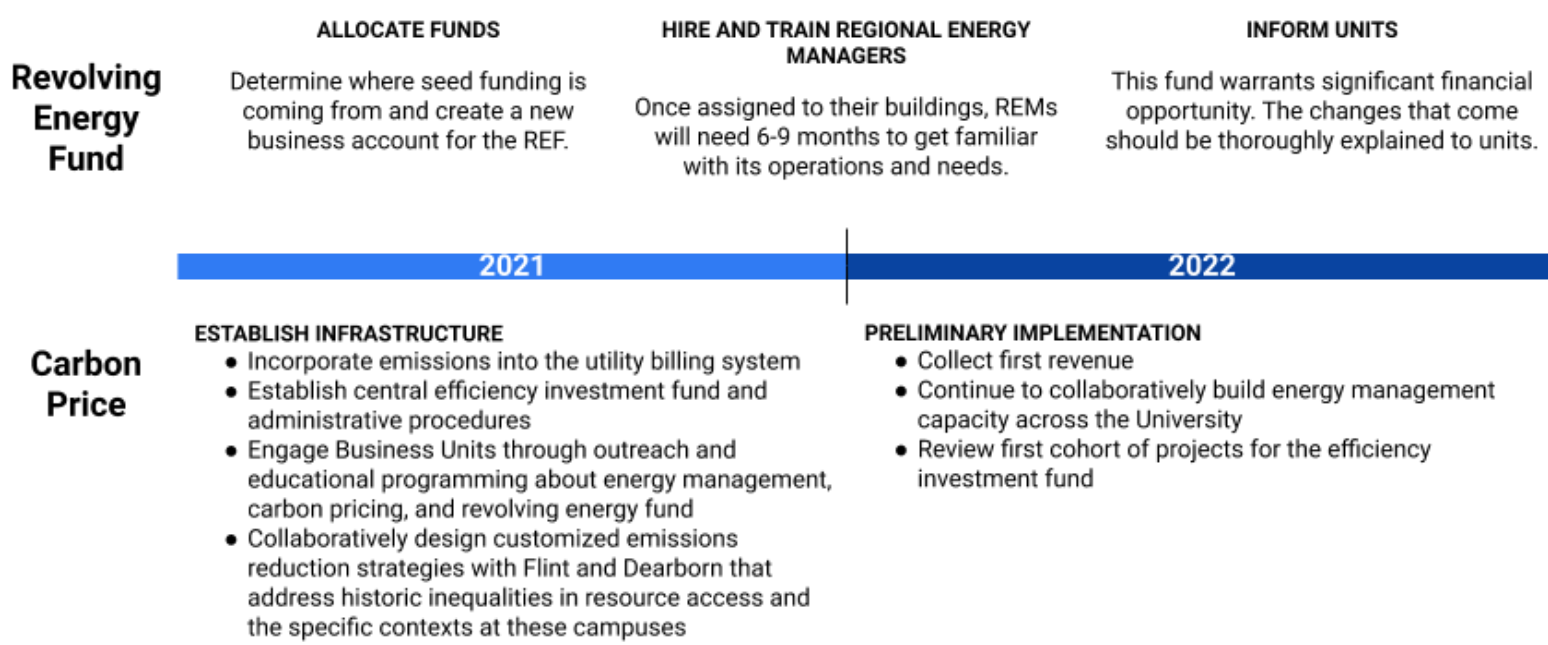

Figure 2. REF and Carbon Price Implementation Timeline through 2022

It is also important to change the structure of utility bills to reflect carbon pricing and add a carbon calculator to Concur to account for air travel. We have received feedback that administrative communication with business units is pertinent when enforcing the carbon price, as this extra line item on their bill will be received negatively unless the social responsibility and long-run economic benefit is explained. In addition, it is critical to create funding for the REF and to begin expanding the staff of energy managers on campus, who are central to making our recommendations work.

Looking ahead, it will be crucial to update our analysis as more data on improvements to existing buildings become available. One important question is how long we can continue finding "low-hanging fruit" that offers carbon abatement at substantially negative costs per ton. A related question is how cost-effective deep retrofits of existing buildings prove to be. Results from the ongoing study by the SmithGroup should be helpful in improving our understanding of such efforts. Our analytical tools can readily incorporate new information as it emerges and update expectations for what is possible from energy consumption policies. 


\section{APPENDICES}

\section{APPENDIX A: Peer Benchmarking}

\section{Revolving Energy Fund}

In order to gain perspective on how REFs are structured and operated, we investigated over 20 institutions that have their own (see list below); all of which are a part of the Billion Dollar Green Challenge. We began identifying the basic components of an REF-administration, project criteria, and financial structure-by using the information found on their websites. Some of the more relevant takeaways from that initial research was that most institutions source their seed funding from the endowment, not many used interest rates, and they varied in who can apply for funding-anyone in the community or those in facilities. We were then able to adapt their models to fit the University's current ECM potential and financial structures. However, the detail provided was certainly lacking and after more investigation, we found it extremely challenging to get in contact with many of the institutions to get more details. Given how trying it was to benchmark, we hope U-M's REF will have clear information on its website for others to learn from as well as an explicit and responsive point of contact.

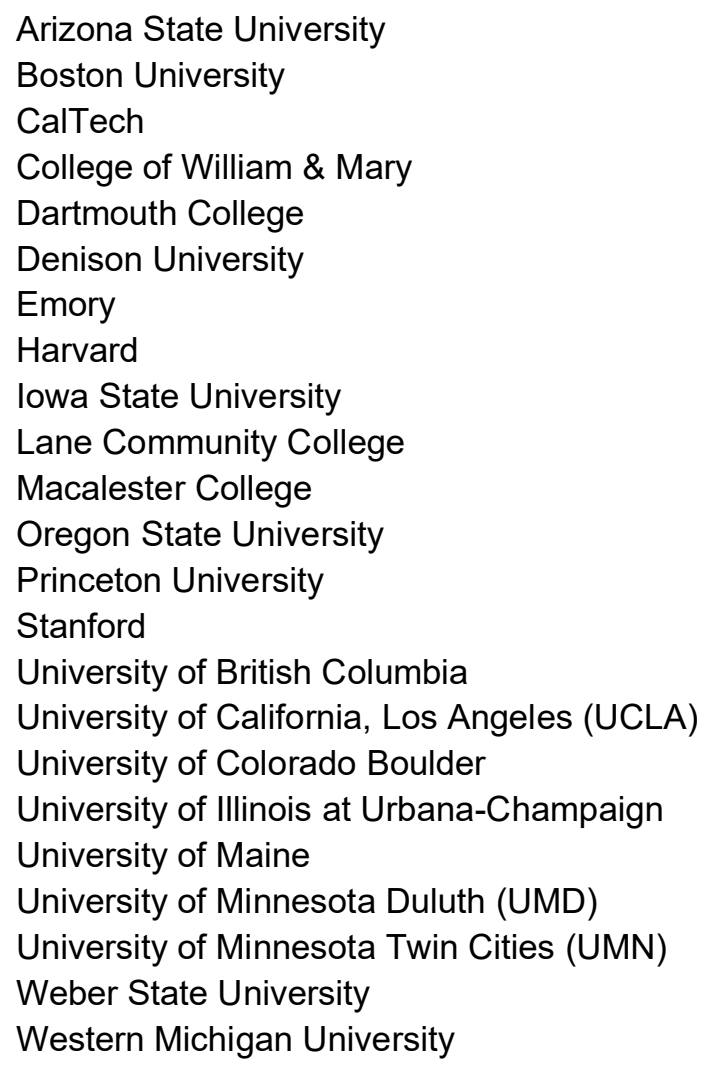

\section{Carbon Price}

Preliminary research on internal carbon pricing began with exploring how peer institutions implement different carbon pricing tools, and the successes and challenges that ensued. We began with Second Nature, an organization committed to encouraging higher education institutions to promote climate action. This knowledge sharing organization featured case studies for carbon pricing strategies at Arizona State University, Cornell University, Smith 
College, Swarthmore College, University of British Columbia, University of California, Los Angeles, University College London, and Yale University. We focused on analyzing Yale, Cornell, Arizona State, and Swarthmore because they were more robust and each took a unique approach that we could learn from. We gained an understanding of carbon pricing terminology and the varying impact of different types of carbon pricing tools, which allowed us to identify the successful features that could be transferable to U-M. From Yale we gained inspiration for the Direct Return funds earmarked for energy efficiency projects, though we adjusted this feature to provide more incentive to business units by providing the outlet of these funds instead of being revenue neutral like Yale. From Cornell we learned the importance of financial obligation by business units to truly incentivize them to decrease their emissions instead of simply making them aware of their impact. Arizona State shed light on some creative solutions in carbon offsets and pricing and how low-cost, simple implementations still make a difference in mitigating emissions. Swarthmore offered an example of how an internal carbon price and a revolving energy fund can be paired together to be most successful. Combining the two approaches by utilizing the revenue generated from the carbon price to fund the REF proved to be the most effective at mitigating emissions through our calculations, which is further backed up by Swarthmore's study.

In presenting our recommendation of an internal carbon price to stakeholders, many remarked that benchmarking the $\$ / \mathrm{MTCO}_{2} \mathrm{e}$ against Yale and Cornell was helpful in grasping the meaning of the price we were suggesting. Peer benchmarking is informative and necessary in gauging the success of a potential policy before it can be implemented. We are confident in the source of our preliminary research to base our version of a carbon price on, while adding additional features to better fit the U-M scale and priorities. Implementing the carbon pricing strategy that we have recommended would get U-M featured on higher education knowledge sharing organizations, such as Second Nature, to acknowledge the university for its pioneering effort at such an impressive new scale so that other peer institutions may learn from it as well. 


\section{APPENDIX B: Analyses Based on GRITS Database}

GRITS is a program created by the Sustainable Endowments Institute that allows institutions to easily track financial, energy, and carbon benefits of resource conservation projects (energy, water, waste). University of Michigan is already a GRITS member and currently uses the platform to track ECMs for the General Fund and, most recently, NCRC. GRITS is used by the OCS Energy Management team to log all ECM projects to date. Details provided in the database include, but are not limited to, project type, capital cost, financial savings, emission savings, simple payback period, \%ROI, and NPV. Since mid-2007, 583 projects have been logged, the majority in General Fund buildings but more recently to include NCRC. Since we only have a clear understanding of the budget and overhead costs of work done in General Fund buildings, filtered out any non-General Fund buildings. We also filtered out any incomplete or archived projects. Furthermore, since the goal of the REF is to reduce emissions, we only included projects with emission savings. Finally, since replenishment of the REF relies on project savings and our particular project selection method is unlikely to fund projects above a 10 -year simply payback period, we filtered out any project with above a 10 -year payback. This leaves 283 projects we believe to be representative of the energy efficiency work U-M could achieve with funding from the REF and carbon pricing recommendations. A summary of the data is shown in the table below.

\begin{tabular}{|l|c|c|c|c|c|c|c|}
\hline & $\begin{array}{c}\text { Simple } \\
\text { Payback (Yrs) }\end{array}$ & $\begin{array}{c}\text { Avg Annual } \\
\text { ROI (\%) }\end{array}$ & $\begin{array}{c}\text { Cost per } \\
\text { MTCO } \mathbf{2} \text { of } \\
\text { abatement } \\
\mathbf{( \$ )}\end{array}$ & $\begin{array}{c}\text { Avg Annual } \\
\text { Energy } \\
\text { Savings } \\
\text { (MMBTU) }\end{array}$ & $\begin{array}{c}\text { Avg Annual } \\
\text { Emissions } \\
\text { Savings } \\
\text { (MTCO } \mathbf{2})\end{array}$ & $\begin{array}{c}\text { Actual } \\
\text { Project Cost } \\
\text { (\$) }\end{array}$ & $\begin{array}{c}\text { Avg Annual } \\
\text { Financial } \\
\text { Savings (\$) }\end{array}$ \\
\hline Mean & 4.04 & 39.77 & $-\$ 47.08$ & 378 & 56.9 & $\$ 26,243.10$ & $\$ 7,555.16$ \\
\hline Median & 3.44 & 22.67 & $-\$ 42.44$ & 93.1 & 18.7 & $\$ 7,449.57$ & $\$ 2,113.36$ \\
\hline First Quartile & 2.26 & 12.72 & $-\$ 51.07$ & 32.2 & 6.3 & $\$ 2,144.00$ & $\$ 752.25$ \\
\hline Third Quartile & 5.52 & 34.36 & $-\$ 31.35$ & 287.7 & 46.3 & $\$ 25,042.00$ & $\$ 5,682.81$ \\
\hline Max Value & 9.93 & 742.52 & $\$ 208.91$ & 6835 & 1006.3 & $\$ 361,167.03$ & $\$ 145,248.53$ \\
\hline Min Value & 0.13 & 5.02 & $-\$ 663.27$ & -401 & -97.2 & $\$ 29.02$ & $\$ 27.00$ \\
\hline
\end{tabular}

The figure below shows the average annual percent ROI of GRITS projects since 2007. There is no sign that we have picked all the "low-hanging fruit," as the return on investment (ROI) of projects in GRITS shows little sign of decreasing over time. Thus, we assume that "low-hanging fruit" will continue to be available in the future and GRITS data will be categorically and financially representative of future reduction efforts, at least up to a $25 \%$ reduction in emissions. Beyond that point, deeper retrofits may be required, for which past data is less representative. 


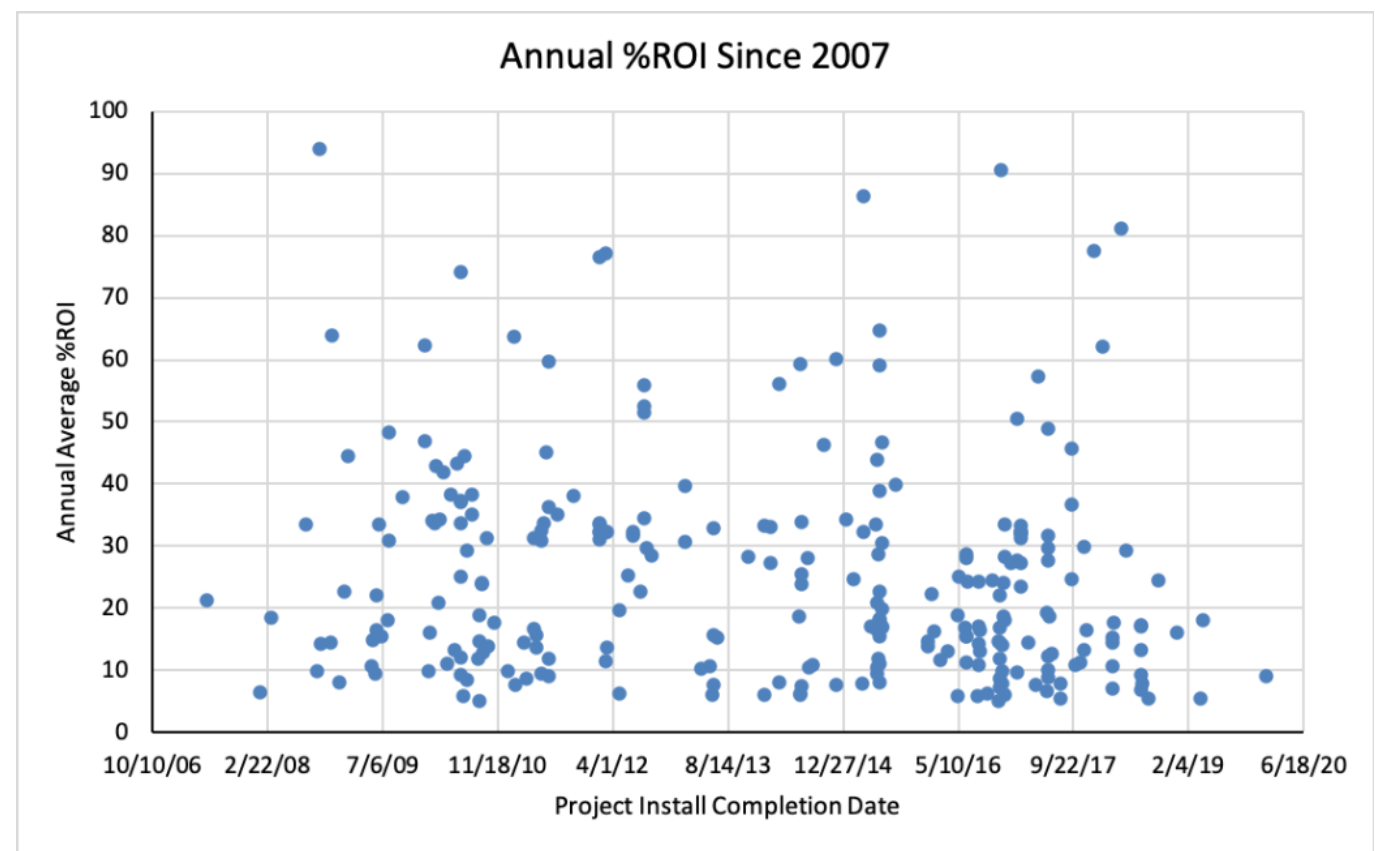

Below is a summary calculation for the cost of abatement including overhead costs. OCS spends \$1.7 million each year in salaries and benefits of the Energy Management Team. Kevin Morgan, who directs the Energy Management team, estimates that about $25 \%$ of the time of his staff is spent proposing, evaluating and implementing ECMs. Thus, we allocate $25 \%$ of the Team's current budget to ECM efforts, which comes to $\$ 430,000$. Adding the NPV of these overhead efforts to the NPV of GRITS projects and then dividing by the lifetime emissions abated, we get a cost of abatement of $-\$ 35.98 / \mathrm{MTCO}_{2} \mathrm{e}$.

\begin{tabular}{|l|c|}
\hline Total Lifetime Emissions Savings & $\$ 321,907.38$ \\
\hline Total Project NPV & $\$ 17,173,187.83$ \\
\hline NPV Labor Costs (since 2008) & $\$ 5,590,000.00$ \\
\hline Fully Loaded COA & $-\$ 35.98$ \\
\hline
\end{tabular}

To calculate the cost of reducing the flow of emissions by one additional ton per year, we begin with historic data on ECM costs and abatement since 2008. We inflate the project costs and additional overhead described above to 2020 dollars using the CPI values listed below. Summing the inflated project and labor costs and dividing by the total estimated annual abatement, we find an incremental cost of $\$ 914$ to cut the flow of emissions by one ton.

\begin{tabular}{|c|c|}
\hline Year & CPI Factor \\
\hline 2007 & 1.27 \\
\hline 2008 & 1.22 \\
\hline 2009 & 1.22 \\
\hline 2010 & 1.19 \\
\hline
\end{tabular}




\begin{tabular}{|l|l|}
\hline 2011 & 1.17 \\
\hline 2012 & 1.14 \\
\hline 2013 & 1.12 \\
\hline 2014 & 1.1 \\
\hline 2015 & 1.1 \\
\hline 2016 & 1.09 \\
\hline 2017 & 1.06 \\
\hline 2018 & 1.04 \\
\hline 2019 & 1.02 \\
\hline
\end{tabular}

\begin{tabular}{|l|r|l|}
\hline Project Costs & $\$ 8,370,256$ & \\
\hline Additional Overhead & $\$ 6,338,200$ & \\
\hline Total Cost & $\$ 14,708,456$ & \\
\hline Annual MTCO $2 \mathrm{e}$ Abated & 16,095 & \\
\hline Annual Marginal Cost & $\mathbf{9 1 3 . 8 3}$ & $\mathbf{\$} / \mathbf{M T C O}_{2}$ e per year \\
\hline
\end{tabular}




\section{APPENDIX C: University Baseline Emissions}

Since our timeline of interest spans 2021-2032, University emissions will look very different than they do in 2020 because both the CPP expansion and PPA with DTE will be in effect at full magnitude (completed in 2021). Thus, we needed to project what the baseline University emissions would be with no reductions from the REF or carbon pricing policies. Ken Keeler provided us with detailed University projections out to 2040 . The U-M baseline from 2021-2032 is as follows:

\begin{tabular}{|c|c|c|c|c|c|}
\hline Emissions 2021 & Emissions 2022 & Emissions 2023 & Emissions 2024 & Emissions 2025 & Emissions 2026 \\
\hline $\mathrm{MTCO}_{2} \mathrm{e}$ & $\mathrm{MTCO}_{2} \mathrm{e}$ & $\mathrm{MTCO}_{2} \mathrm{e}$ & $\mathrm{MTCO}_{2} \mathrm{e}$ & $\mathrm{MTCO}_{2} \mathrm{e}$ & $\mathrm{MTCO}_{2} \mathrm{e}$ \\
\hline $\mathbf{5 5 8 , 8 0 1}$ & 414,313 & 408,560 & 405,134 & 405,661 & 403,121 \\
\hline
\end{tabular}

\begin{tabular}{|c|c|c|c|c|c|}
\hline Emissions 2027 & Emissions 2028 & Emissions 2029 & Emissions 2030 & Emissions 2031 & Emissions 2032 \\
\hline $\mathrm{MTCO}_{2} \mathrm{e}$ & $\mathrm{MTCO}_{2} \mathrm{e}$ & $\mathrm{MTCO}_{2} \mathrm{e}$ & $\mathrm{MTCO}_{2} \mathrm{e}$ & $\mathrm{MTCO}_{2} \mathrm{e}$ & $\mathrm{MTCO}_{2} \mathrm{e}$ \\
\hline 403,969 & 400,720 & 399,326 & 385,894 & 387,259 & $\mathbf{3 8 3 , 4 2 9}$ \\
\hline
\end{tabular}

Table C1. U-M Ann Arbor Baseline Emissions Projection 2021-2032

\section{Justification of $\mathbf{2 5 \%}$ Reduction in Emissions vs. $25 \%$ Reduction in BTUs}

Since we have limited information on the speed and magnitude of energy reduction potential of buildings on campus, we based our abatement goals on Engie's guaranteed energy use intensity (EUI) reduction for Ohio State University of $25 \%$ over 10 years. ${ }^{14}$ Our calculations rely heavily on estimates of the incremental cost to achieve an annual reduction of one ton of annual emissions. Therefore, we wanted to confirm that a $25 \%$ reduction in BTUs over 10 years is equivalent to a $25 \%$ reduction in emissions over the same period.

To do this, we looked at historical GRITS data to determine which energy source our BTU reductions come from. We found that over the past 13 years, $57.2 \%$ of BTU reductions have come from electricity, $41.5 \%$ from steam, and $1.3 \%$ from natural gas. Current U-M emission projections attribute all BTUs from the CPP to natural gas whereas GRITS looks at downstream reductions in electricity and steam. To account for this, we divided natural gas into BTUs attributable to the CPP and those attributable to other end uses. Assuming 50\% of CPP natural gas BTUs become electricity and $50 \%$ become steam, we get the following breakdown of "Current BTUs." Holding the reduction split from GRITS constant, we aim for the following BTU reductions over 10 years:

\begin{tabular}{|l|c|}
\hline & BTUs \\
\hline Natural Gas CPP & $3,794,634,366,060$ \\
\hline Natural Gas Other & $1,753,465,633,940$ \\
\hline
\end{tabular}

Table C2. Natural Gas Attributable to CPP and Other Uses 


\begin{tabular}{|l|r|r|}
\hline & \multicolumn{1}{|c|}{ Current BTUs } & 25\% BTU Reduction \\
\hline Electricity & $3,279,582,183,030$ & $991,042,195,000$ \\
\hline Steam & $1,897,317,183,030$ & $719,025,368,750$ \\
\hline NG & $1,753,465,633,940$ & $22,523,686,250$ \\
\hline Total & $6,930,365,000,000$ & $1,732,591,250,000$ \\
\hline
\end{tabular}

Table C3. 25\% Reduction in BTUs by Source

Assuming a linear reduction over 10 years and using the same emissions factors from the Ken Keeler projection, we converted this BTU reduction to an emissions reduction. Buying 200,000 MWh of "emissions-free" energy changes the effective emissions intensity of the DTE electricity on the Ann Arbor campus. For example, the pre-PPA emissions intensity of DTE electricity is $0.00068 \mathrm{MTCO}_{2} \mathrm{e} / \mathrm{kWh}$. This would originally result in $152,066 \mathrm{MTCO}_{2} \mathrm{e}$ but because $200,000 \mathrm{MWh}$ of emissions-free energy avoids $128,837 \mathrm{MTCO}_{2} \mathrm{e}$, this emissions intensity drops to $0.000098 \mathrm{MTCO}_{2} \mathrm{e} / \mathrm{kWh}$. Furthermore, since DTE's grid is getting cleaner over time, this effective emissions intensity is also declining over time. In order to correctly account for both of these factors, we use the "effective emissions factor" for DTE in our calculations.

\begin{tabular}{|l|r|r|r|r|r|r|}
\hline & $\mathbf{2 0 2 1}$ & $\mathbf{2 0 2 2}$ & $\mathbf{2 0 2 3}$ & $\mathbf{2 0 2 4}$ & $\mathbf{2 0 2 5}$ & $\mathbf{2 0 2 6}$ \\
\hline MT/BTU & $1.84 \mathrm{E}-07$ & $2.35 \mathrm{E}-07$ & $2.23 \mathrm{E}-07$ & $2.16 \mathrm{E}-07$ & $2.17 \mathrm{E}-07$ & $2.12 \mathrm{E}-07$ \\
\hline $\mathrm{MT} / \mathrm{kWh}$ & $6.29 \mathrm{E}-04$ & $8.04 \mathrm{E}-04$ & $7.62 \mathrm{E}-04$ & $7.37 \mathrm{E}-04$ & $7.41 \mathrm{E}-04$ & $7.22 \mathrm{E}-04$ \\
\hline & \multicolumn{7}{|c|}{$\mathbf{2 0 2 7}$} & $\mathbf{2 0 2 8}$ & $\mathbf{2 0 2 9}$ & $\mathbf{2 0 3 0}$ & $\mathbf{2 0 3 1}$ & $\mathbf{2 0 3 2}$ \\
\hline MT/BTU & $2.13 \mathrm{E}-07$ & $2.06 \mathrm{E}-07$ & $2.03 \mathrm{E}-07$ & $1.75 \mathrm{E}-07$ & $1.78 \mathrm{E}-07$ & $1.70 \mathrm{E}-07$ \\
\hline $\mathrm{MT} / \mathrm{kWh}$ & $7.28 \mathrm{E}-04$ & $7.05 \mathrm{E}-04$ & $6.94 \mathrm{E}-04$ & $5.97 \mathrm{E}-04$ & $6.07 \mathrm{E}-04$ & $5.79 \mathrm{E}-04$ \\
\hline
\end{tabular}

Table C4. DTE Effective Emissions Intensity 2021-2032

A $25 \%$ reduction in BTUs results in a $29.5 \%$ reduction in emissions, validating our assumption that these are effectively equal reductions, our emissions reduction being slightly conservative.

Annual Reduction Natural Gas: 7,039.44 $\mathrm{MTCO}_{2} \mathrm{e}$

Annual Reduction Electricity: 5,213.61 $\mathrm{MTCO}_{2} \mathrm{e}$

Total Reduction from 2022 Baseline: 122,530.51 $\mathrm{MTCO}_{2} \mathrm{e}$ Total Reduction Percentage: $29.5 \%$ 


\section{APPENDIX D: Revolving Energy Fund}

\section{APPENDIX D.1: REF Operation}

The logistics of operating the REF are described in detail below. We envision a five-stage process.

\section{Stage 1: Project Identification + Submission}

Each Unit's REM(s) will identify and create project proposals to submit to the REF. A Unit may bundle two projects to submit as one proposal to increase the value of a project that would not otherwise be competitive individually. See examples of singular and bundled proposals in Appendix C.

\section{Stage 2: Technical Review + Rank}

Each project will be reviewed by the Lead(s) and/or Assistant(s) of the REF team to determine which ones need to be reviewed by the TC and which ones can be expedited to the ranking stage. ${ }^{15}$ The TC will verify both engineering and financial calculations are correct. After the TC approves a project, it moves on to the ranking stage. A spreadsheet algorithm will rank projects in order of cost of abatement (COA) in $\$ / \mathrm{MTCO}_{2} \mathrm{e}$. In the event that two projects have the same COA, the project with a greater annual emissions abated will be ranked higher. We believe COA is the best metric because it incorporates both the quantity of emissions reduced as well as financial factors such as $\mathrm{ROI}$ and present value. This framework will identify a pathway to achieve the greatest emissions reduction at the lowest cost to the University.

The Lead(s) should be continually monitoring the ranking system to ensure it is operating as envisioned, that is, the order is logical and competitive projects are not left behind. Lead(s) can re-evaluate the ranking system if it becomes inequitable, given the support of $66 \%$ of the SC. Finally, queued projects rolling over to the next fiscal year will be annually updated by the REF team with current utility rates, material costs, and emissions factors. A project can do this $3 x$ before the REM is required to fully resubmit.

\section{Stage 3: Selection for Funding}

The Lead(s) and/or Assistant(s) will select for detailed consideration top projects in ranked order up to $120 \%$ of the available funds in a given funding cycle (or two additional projects, whichever has greater monetary value). The SC will ultimately choose a subset of these projects totaling up to $100 \%$ of the available funding. At an annual cost of abatement of $\$ 520 / \mathrm{MTCO}_{2} \mathrm{e}$, the fund balance must be at least $\$ 9.5 \mathrm{M}$ at the start of each fiscal year to achieve the annual emissions reduction goal. These numbers are based off of historic project costs and annual savings and should be updated every 3 to 5 years. See Appendix E for calculations.

There are three funding cycles per year. At the beginning of Fall, Winter, and Spring semesters, ${ }^{16}$ the SC will meet to select projects to fund. To ensure preparedness and efficiency, committee members will review projects prior to the meeting. Any Unit with a project under consideration is invited to attend the selection meeting; their invitation will state whether the committee has any further questions they want addressed. The SC will submit the list of projects they approved for each funding cycle to the Lead(s) for final approval.

A note on equity: Because all units will receive equal support from their REM to identify energy efficiency projects, all units will have a fair chance at receiving funding based on the need of their building(s). Units with buildings that have not recently been renovated will have a larger need for project funding than units with newly renovated buildings. The goal of the REF is to 
support carbon neutrality as quickly as possible by prioritizing projects with lowest cost of emissions reduction.

\section{Stage 4: Final Contract}

Once a project has been selected for funding, the Unit's financial representative, corresponding REM, and Lead(s) will come together to sign a contract outlining the terms of the loan. The contract will include the following as a bare minimum:

1. Payback structure: As mentioned previously, an REF loan is paid back through the financial savings it accrues each year. In the contract, the project owner will select one of the two following loan repayment structures:

Option 1: Annual payment is $100 \%$ of the estimated savings of the project.

Option 2: Annual payment is $75 \%$ of the estimated savings of the project.

After consulting various campus units, we identified a need to provide two repayment options. Smaller units frequently expressed concern about realized financial savings falling short of those estimated in the proposal, while larger units tended to be more confident in their ability to handle small estimation differences. Option 1 places the full burden of risk onto the unit in the short run if estimated savings are not fully realized. Option 2 provides added flexibility for units with tighter budgets and less confident estimates, stretching out loan repayment over a greater number of years.

Both options will charge an interest rate of $4.5 \% .{ }^{17}$ This will account for inflation and allow the fund to grow over time. Fund growth is important because it will allow the University to fund more capital-intensive projects over time, which is particularly valuable when we begin to run out of "low-hanging fruit" options. Both options will also charge $1 \%-3 \%$ of the project capital cost for measurement and verification (M\&V). ${ }^{18}$ Annual payments to the fund will be due on June 30th, the end of the fiscal year. The first year of a project will be prorated according to the installation completion date.

2. Construction timeline: The construction timeline of the project will include start date, milestones, and expected completion date/date of operation. This is important for calculating the adjusted first year payment to the fund.

3. Risk acknowledgement: There will be a clause acknowledging that the Unit is responsible for meeting the terms outlined in the payback structure and will assume any risk associated with incorrectly estimated savings, weather, building demand, etc.

4. Accountability acknowledgement: The Unit and respective REM will agree to be held accountable for providing the relevant information outlined in post-construction responsibilities.

\section{Stage 5: Post-Construction Responsibilities}

To measure the success of the fund, ensure its continued operation, and provide transparency for U-M stakeholders and community members, the following is required upon receiving funding from the REF.

I. Unit Level Responsibilities

A. Annual Loan Repayment

B. Measurement and Verification (M\&V): $M \& V^{19,20}$ will be critical to ensure accurate reporting to our stakeholders. Projects must report energy savings and emissions abated at the end of the fiscal year for a minimum of 10 years beyond the installation completion date. The project REM will be responsible for ensuring M\&V is executed and reported. 
**IMPORTANT: We fully acknowledge current M\&V practices at U-M are inadequate to support the efforts of carbon neutrality and must be overhauled for the REF to function effectively and sustainably. Conversations with the OCS Energy Management Team have confirmed the ability to handle the redesign of $M \& V$ to meet the needs of the fund.

C. Public Relations (PR) Availability: Unit representatives will respond to any PR requests from the REF team (see below).

II. REF Level Responsibilities

A. Financial status of the fund: Lead(s) and/or Assistant(s) will track the financial progress of the fund (i.e. flow of all project savings) and enforce the payment structure. The GRITS Green Revolving Fund (GRF) mode could assist in tracking. See Appendix D.7.

B. Transparency and PR: U-M will hire at least one PR coordinator to advertise the impact of the REF. This increases transparency in the University's progress to carbon neutrality and encourages use of the REF. 


\section{APPENDIX D.2: Unit Breakdown and List}

These units will receive support from their designated REM to propose projects to the REF that reduce energy consumption. Many REMs will be shared between smaller units, which should be organized by building, similar to the method used to divide up REM coverage currently.

\section{Academic Units ${ }^{21}$}

- Alfred Taubman College of Architecture and Urban Planning

- Penny W. Stamps School of Art \& Design

- Stephen M. Ross School of Business

- School of Dentistry

- School of Education

- College of Engineering

- School of Environment \& Sustainability

- Horace H. Rackham School of Graduate Studies

- School of Information

- School of Kinesiology

- Law School

- College of Literature, Science, and the Arts

- Medical School

- School of Music, Theatre \& Dance

- School of Nursing

- College of Pharmacy

- School of Public Health

- Gerald R. Ford School of Public Policy

- School of Social Work

Auxiliary Units

- Athletics

- Hospital System

- Housing and Unions

- $\quad$ North Campus Research Complex

Non-tuition Receiving Units $^{22}$

(Budgetary Affairs)

- Office of Budget and Planning

(Engaged Learning)

- Alliance for the Arts in Research

Universities

- Detroit Center

- Graham Sustainability Institute

- Poverty Solutions

- Wallace House

- Women in Science and Engineering
- Air Force Officer Education

- Army Officer Education

- Navy Officer Education

(Academic Innovation \& University Library)

- University Library

- Center for Research on Learning and Teaching

- Center for Academic Innovation

(Enrollment Management)

- Office of Financial Aid

- Office of New Student Programs

- Office of the Registrar

- Office of Undergraduate Admissions (Academic and Faculty Affairs)

- Academic Human Resources

- ADVANCE

- CEW+

(Equity and Inclusion)

- Office of Academic Multicultural Initiatives

- Center for Educational Outreach

- Wolverine Pathways

(Graduate Studies)

- Arts Consortium

- Cultural Collections Council

- Bentley Historical Library

- Matthaei Botanical Gardens and Nichols Arboretum

- Museum of Art

- William L. Clements Library

(No Broader Category)

- Life Sciences Institute

- Institute for Social Research

- Office for Institutional Equity 
APPENDIX D.3: REF Personnel

\begin{tabular}{|c|c|}
\hline Role & Responsibilities \\
\hline Lead & $\begin{array}{l}\text { 1. Track overall status of the fund-total fund size, current } \\
\text { balance, payment statuses } \\
\text { 2. Determine available funds for each selection cycle } \\
\text { 3. Approve and/or determine construction and operating date } \\
\text { for each project } \\
\text { 4. Give final signing approval for each project funded } \\
\text { 5. Follow-up with any missing or late payments } \\
\text { Additional authoritative capacity: } \\
\text { - Can override rank order for time sensitive projects }{ }^{23} \text { or to meet } \\
\text { the annual emissions goal } \\
\text { - Initiate re-evaluation of ranking system with } 66 \% \text { support of } \\
\text { Selection Committee }\end{array}$ \\
\hline Lead Assistant(s) & $\begin{array}{l}\text { 1. Monitor REM proposal rate and quality to ensure REF is } \\
\text { fully utilized. Additionally, at the end of each FY, send a list } \\
\text { of currently queued projects and their ranks to REMs and } \\
\text { Unit Representatives. } \\
\text { 2. Aid lead in overseeing project and fund finances } \\
\text { 3. Provide organizational assistance to REF lead and other } \\
\text { REF personnel } \\
\text { 4. Hire and supervise intern(s), if needed }\end{array}$ \\
\hline $\begin{array}{l}\text { Regional Energy } \\
\text { Managers (REMs) }\end{array}$ & $\begin{array}{l}\text { 1. Identify projects and submit REF proposals for their } \\
\text { assigned units } \\
\text { 2. Collect and report M\&V data for their respective list of } \\
\text { funded projects }\end{array}$ \\
\hline Technical Committee & $\begin{array}{l}\text { Modeled from current Energy Conservation Committee (ECC). }{ }^{24} \text { It's } \\
\text { members currently include representatives from OCS (1), AEC } \\
(2),{ }^{25} \text { faculty (1), utilities (1). }\end{array}$ \\
\hline Selection Committee & $\begin{array}{l}\text { Composed of no more than } 9 \text { representatives from the following } \\
\text { units (should always be an odd number of people for voting } \\
\text { purposes) } \\
\text { - Finance } \\
\text { - Architecture, Engineering, and Construction (AEC) } \\
\text { - Building Automation System (BAS) } \\
\text { - Facilities and Operations } \\
\text { - Utilities }\end{array}$ \\
\hline Rollout Committee & Ensures REMs and all other individuals that work for or with the \\
\hline
\end{tabular}




\begin{tabular}{|l|l|}
\hline & $\begin{array}{l}\text { REF understand how the REF functions and why. These people will } \\
\text { organize an event, similar to a training retreat where everyone } \\
\text { involved in the REF gets a chance to prepare themselves to } \\
\text { optimally utilize the fund. }\end{array}$ \\
\hline $\begin{array}{l}\text { Public Relations } \\
\text { Coordinator(s) }\end{array}$ & $\begin{array}{l}\text { 1. Post a summary of each project funded to a public REF } \\
\text { webpage. The website is for transparency and educational } \\
\text { purposes and thus, should be public, easy to locate, and } \\
\text { easy to navigate. }\end{array}$ \\
& $\begin{array}{l}\text { 2. Run REF/OCS social media accounts. Posts should be } \\
\text { made to each account at least once per month highlighting } \\
\text { REF efforts and ongoing REF projects on campus. }\end{array}$ \\
\hline Intern(s) & $\begin{array}{l}\text { The REF presents an excellent opportunity for students interested } \\
\text { in the energy field to get professional experience in an academic } \\
\text { setting. Below are various ways in which student interns could be } \\
\text { integrated into the implementation of an REF. } \\
\text { 1. Aid REMs in proposal development and submission } \\
\text { 2. Aid in REF administrative responsibilities } \\
\text { 3. PR Coordinator }\end{array}$ \\
\hline
\end{tabular}




\section{APPENDIX D.4: Example Proposals}

Shown below is what the first page of each project proposal should look like-an agreement statement between the Unit and REF personnel, a brief summary that covers important information from all sections of the proposal, and titles of attached work (project specs and metrics calculations). Upon approval, a financial contract will be created using a few points from the proposal (see "Stage 4: Financial Contract" in recommendation). All REMs will have access to these proposal templates.

The required sections for each proposal include:

- Executive summary with important metrics

- Background

- Project Description

- Estimated Annual Savings (total and by resource)

- Estimated Carbon Reduction Impact

- Estimated Cost of Abatement

- Estimated Project Cost

- Estimated Payback Period

- Maintenance Impact

The bolded metrics are extremely important for REF functionality-the total annual savings is the amount required to be paid back each year, the estimated cost of abatement determines the project's rank against others requesting funding, and the estimated payback period determines the length of the repayment contract.

The following shows two scenarios of proposals - a more common, singular proposal and a bundled proposal. The singular proposal for the MSRB III requires nothing more than what is described above. The bundled proposal for the Chemistry building requires everything described above for both projects and must communicate the final metrics are dependent on these two different projects on the cover page and in the executive summary. The example provided was not proposed together, but is representative of project bundling parameters: both projects must belong to one Unit and be proposed simultaneously. When bundled, this proposal looks more attractive, this is what the addition would look like:

Bundled Cost: $\$ 85,900+\$ 142,000=\$ 100,100$

Bundled Estimated Savings: $\$ 164,500+\$ 14,050=\$ 178,550 /$ year

Bundled Payback Period: 0.56 years

${ }^{* *}$ Bundled Estimated Cost of Abatement: \$15.4/MT $\rightarrow$ determines ranking

${ }^{* *}$ Project 1 Estimated Abatement over 20 years: 6000 MT

**Project 2 Estimated Abatement over 20 years: 500 MT

${ }^{* *}$ Project 1 Estimated Cost of Abatement: \$14.31/MT

**Project 2 Estimated Cost of Abatement: \$284/MT

**These are mock numbers used as an example. 


\title{
Single Project Proposal
}

Medical Science Research Building III—Winter Chilled Water Installation

\section{UNIVERSITY OF MICHIGAN Energy Conservation Measure Agreement}

\author{
Project Name: ECM - Winter Chilled Water \\ SUBMITTED BY: David $\mathrm{Oz}$ \\ BUILDING: MSRB III \\ DATE: \\ September 05, 2019 \\ This Energy Conservation Measure Agreement constitutes an understanding between the Medical College \\ (MED) and Facilities \& Operations (F\&O) concerning the implementation of an Energy Conservation Measure \\ which will be funded through the U-M Energy Conservation Project Account. \\ MED acknowledges that the scope of the project is understood and that every effort will be made to comply with \\ the critical operating parameters listed within for at least the duration of the calculated payback period. It is \\ understood that MED will be given an opportunity to review the construction plans and specifications and that \\ the construction work will also be coordinated with the region trades. Also, all construction work will be \\ coordinated with the building occupants and with any other on-going construction projects in the areas to \\ minimize disruptions to the occupants.
}

\section{DESCRIPTION:}

The proposed project will install chilled water generating coils in outdoor air streams to unload steam coils and generate winter chilled water more efficiently.

SUMMARY INFORMATION:

FY2019 BuILding Energy USAGE AND Costs:

Estimated Project Cost:

Estimated Cost Savings:

Estimated Payback Period:

Estimated Electricity Savings:

Estimated Steam Savings:

Estimated Water Savings:

Estimated Carbon Impact:

$\$ 740,000$
$\$ 100,000 /$ year
7.4 years
$60,000 \mathrm{kWh} /$ year
$5,800 \mathrm{MMB}$ /u/year
$840 \mathrm{CCF} /$ year
$400 \mathrm{MTCO} /$ year

Electricity: $\quad 10,205,754 \mathrm{kWh} \quad \$ 857,283$

CPP-Steam: $\quad 64,968 \mathrm{MMBtu} \$ 991,405$

Stormwater: $\quad 5$ AIA $\$ 1,731$

Water: $\quad 18,565 \mathrm{CCF} \quad \$ 194,727$

Total: $\$ 2,045,146$

ATTACHMENTS:

ECM for MSRB -1, 2 \& 3-ECM Winter Chilled Water (pg. 1-3)

Appendix A - Areas of Work (pg. 4-5)

Appendix B - Chilled Water Flow Diagrams (pg. 6)

Appendix C - AHU General Arrangements (pg. 7-8)

Appendix D - System Control Points (pg. 9)

Appendix E - Estimated Savings (pg. 10-18)

Appendix F - Estimated Construction Cost (pg. 19-23) 


\section{Bundled Project Proposal}

Chemistry Building-Atrium Lab Sensors \& Laboratory HVAC System Upgrade

\section{Project 1:}

\section{UNIVERSITY OF MICHIGAN Energy Conservation Measure Agreement}

Project Name: Atrium Lab Sensors (Revision 1) Bullding: Chemistry Building

SUBMITTED BY:

DATE:

June 23, 2008

This Energy Conservation Measure Agreement constitutes an understanding between the College of Literature, Science, \& the Arts (LS\&A), and the Utilities and Plant Engineering Department, concerning the implementation of an Energy Conservation Measure in a building occupied by the College of LS\&A, which will be funded through the U-M Energy Conservation Project Account.

The College of LS\&A acknowledges that the scope of the project is understood and that every effort will be made to comply with the critical operating parameters listed below for at least the duration of the calculated payback period. It is understood that the College of LS\&A will be given an opportunity to review the construction plans and specifications and that the construction work will also be coordinated with the College of LS\&A.

\section{DESCRIPTION:}

This project will upgrade the Chemistry Building atrium level teaching labs to install controls for the lighting and HVAC systems with occupancy sensors. All savings for this project are based on HVAC loads only, lighting savings were deemed to be minimal.

\section{Critical Operating Parameters:}

Rooms will maintain at least $10 \mathrm{ACH}$ under all conditions per conversation with $\mathrm{M}$. Hanna During unoccupied periods the laboratory personnel will move all chemicals to designated storage hoods.

SUMMARY INFORMATION:

FY2007 BUILDING ENERGY COSTS

$\begin{array}{llll}\text { Estimated Project Cost: } & \$ 85,900 & \text { Electricity: } & \$ 1,244,178.90 \\ \text { Estimated Cost Savings: } & \$ 164,500 / \mathrm{yr} & \text { Steam: } & \$ 2,973,314.20 \\ \text { Estimated Btu Savings: } & 6,835 \times 10^{6} \mathrm{Btu} / \mathrm{yr} & \text { Water \& Sewer: } & \$ 188,111.52 \\ \text { Estimated Payback Period: } & 0.5 \text { years } & & \end{array}$

\section{ATTACHMENTS:}

ECM for Chemistry Building - Atrium Lab Sensors (Revision 1)

Appendix A - Estimated Energy Savings in Reducing Outside Airflow - Per CFM

Appendix B - Estimated Construction Cost 
Project 2:

\section{UNIVERSITY OF MICHIGAN Energy Conservation Measure Agreement}

PROJECT NAME: Laboratory HVAC System Upgrade - Phase 2 BUILDING: Chemistry Building ('88 Section)
SUBMITTED BY:

DATE:

July 28,2008

This Energy Conservation Measure Agreement constitutes an understanding between the College of Literature, Science, \& the Arts (LS\&A) and the Utilities and Plant Engineering Department, concerning the implementation of an Energy Conservation Measure in a building occupied by the College of LS\&A, which will be funded through the U-M Energy Conservation Project Account.

The College of LS\&A acknowledges that the scope of the project is understood. It is understood that the College of LS\&A will be given an opportunity to review the construction plans and specifications and that the construction work will also be coordinated with the College of LS\&A.

\section{DESCRIPTION:}

The proposed project will upgrade the HVAC system in 3 laboratories to a modulating VAV system with Phoenix control. This will be incorporated into the AEC IMF project - Phase VI.

\section{SUMMARY INFORMATION:}

Estimated Project Cost:

Estimated Cost Savings:

Estimated Electric Savings:

Estimated Cooling Savings:

Estimated Steam Savings:

Estimated Payback Period:

$\$ 142,000$
$\$ 14,050 / \mathrm{yr}$
$12,356 \mathrm{kWh} / \mathrm{yr}$
$219.7 \times 10^{6} \mathrm{Btu} / \mathrm{yr}$
$319.5 \times 10^{6} \mathrm{Btu} / \mathrm{yr}$
10.1 years

FY2007 BUILDING ENERGY COSTS

Electricity: $\quad \$ 1,244,178.90$

Steam: $\quad \$ 2,973,314,20$

Water \& Sewer: $\quad \$ 188,111,52$

ATTACHMENTS:

ECM for Chemistry Building - Laboratory HVAC System Upgrade - Phase 2 Appendix A - Schematic Design

Appendix B - Heat Load Calculations

Appendix C-Room 2606 Airflow Data

Appendix D-Summary of Outside Airflow Savings - Per CFM

Appendix E - Airflow Savings - Room Details

Appendix F - Reduced Horsepower Savings

Appendix G - Estimated Construction Cost - 2 Hood Laboratory

Appendix H - Estimated Construction Cost -5 Hood Laboratory

- - . . . . - n 


\section{APPENDIX D.5: Expedited Project Categories}

There are two ways a project gets moved into the ranking stage: immediately upon initial review or following an additional technical review. The project type, device swap or systematic upgrade, and the upfront capital cost determine the path to the ranking stage.

A device swap is when the project scope simply exchanges an outdated device for a more efficient one (e.g., changing out incandescent light bulbs with more efficient LEDs). If a device swap is under $\$ 75,000$ in capital cost, the project will be immediately sent to the ranking stage. Any device upgrade above this cost threshold will be sent to the Technical Committee.

When the project scope involves controls, varying load, is reliant on multiple variables (i.e. sensors that track room activity for resource usage), and/or has a high likelihood of greater system changes, the project will require additional review from the Technical Committee. All systematic upgrade projects will require additional review-there is no cost threshold for these projects. 


\section{APPENDIX D.6: M\&V 1\%-3\% Breakdown}

As mentioned in the REF operation details in Appendix D.1, both contracting options will charge between $1 \%$ and $3 \%$ of the project capital cost to cover $M \& V$ expenses. The revenue from this line item will be held separately from the REF and used for installing and maintaining any equipment necessary to track the performance of the project. This will not impact project ranking in the queue-cost of abatement will only use the pre-M\&V capital cost.

This separate M\&V pot will be fluid between projects to ensure that every project is able to fund the necessary M\&V. Any excess M\&V capital from a single project can be used to fund other projects whose M\&V capital comes up short. We acknowledge that often the larger projects are the ones who have savings that can be measured in building-level meters. Therefore, they would not need as much M\&V because it already exists. Thus, we recommend that projects with capital costs below $\$ 100,000$ will be charged $3 \%$ for M\&V and those exceeding $\$ 100,000$ will be charged $1 \%$ for $M \& V$. Furthermore, if the project owner believes $M \& V$ equipment costs will be $\$ 0$, they can apply to waive the M\&V charge. The REF Lead will be responsible for reviewing these waiver requests and approving them.

NOTE: We were recommended a wide range of values for this cost threshold. This is not set in stone and should be given more consideration before implementation. Alternatively, the REF could implement a straight $2 \%$ fee across the board with the assumption that it will see a relatively even split between larger and smaller projects. This would eliminate the need for determining a cost threshold. 


\section{APPENDIX D.7: GRITS GRF Mode}

GRITS is a program created by the Sustainable Endowments Institute that allows institutions to easily track financial, energy, and carbon benefits of resource conservation projects (energy, water, waste). University of Michigan is already a GRITS member and currently uses the platform to track ECMs for the General Fund and, most recently, NCRC. GRITS additionally has a Green Revolving Fund (GRF) mode ${ }^{26}$ that could make the tracking of an REF $^{27}$ easy.

In this mode, GRITS handles the tracking of required payments to the fund, current fund size, and total fund value. The University can specify the start date of the fiscal year to ensure savings and loan repayments are calculated across the correct time frame. GRITS will automatically prorate the first year a project is implemented based on the logged install completion date. Furthermore, one can see lifetime investments and savings from the fund.

In GRF mode, U-M can also set the percentage of project costs to return to the fund, the interest rate, and an after repayment, which is a fixed percentage of the initial project cost that must be repaid to the fund in addition to the original loan (i.e., $120 \%$ on a $\$ 50 \mathrm{k}$ project results in repaying $\$ 60 \mathrm{k}$ to the fund). In the event of a donor or other cash infusion, GRITS is able to label the transaction as a capital deposit.

Other features that exist in both the regular program and GRF mode but are important to highlight include the ability to customize resource ${ }^{28}$ price and carbon emission factors. In these sections we can set our resource prices to match those of DTE or the mix from the central plant. Similarly, we can alter the carbon emission factors to reflect our local energy mix as well as efforts yielding a cleaner grid over time.

Should an REF be implemented at U-M, we recommend investigating the use of this tracking tool. 


\section{APPENDIX D.8: REF Model}

\section{Model Description}

To better understand the operational aspect of an REF and determine seed funding, we created a representative model that analyzes cash flow sensitivity to simple payback period, seed funding, interest rate, and annual capital expenditure. The model also allows for the user to include projected carbon tax revenues into the REF. We focused primarily on analyzing the first quartile, average, and third quartile simple payback periods of existing GRITS data; these were found to be $2.26,4.04$, and 5.52 years, respectively. The model divides the capital expenditure each year by the simple payback period to calculate the annual payment back to the REF. This amount is then adjusted for the given interest rate to calculate the discounted payback period and future value of the project. The user can select a given simple payback period, seed funding size, interest rate, and capital expenditure amount to determine how the fund size will change over time.

\section{Seed Funding}

To determine the necessary REF seed funding, we utilized the REF model with an average simple payback period of 4.04 years. Based on the escalating cost of abatement derived in Appendix B, our 10-year emissions reduction goal, and the spending assumptions in the REF model, we backed out a seed fund of $\$ 24$ million.

\section{Analyzing the Combined Recommendation}

To analyze our three recommendations we created three models: one where the REF is funded solely through seed funding, one where the REF is funded solely by the carbon price, and one where seed funding and carbon price are combined to fund the REF. These models were created under the assumption of an average simple payback period (4.04 years). For the REF only and REF + Carbon Price model, the minimum fund size was set to $\$ 1,000,000$, so after five years the fund would maintain an ending balance of $\$ 1,000,000$. Both funds begin at a $\$ 24,000,000$ seed fund. The carbon price only model has a minimum fund size of $\$ 0$. The Figure D1 shows how capital expenditure per year will vary based on these three options.

Minimum Fund Balance: The purpose of determining a minimum fund balance is to ensure that the fund can cushion any deviations in project savings and payback periods. To account for uncertainties, we believe at least $\$ 1$ million should remain in the fund at all times. 


\section{Capital Expenditure per Year with 4\% Interest Rate}

REF Only $\square$ Carbon Price Only $\square$ REF +Carbon Price

$\$ 60,000,000.00$

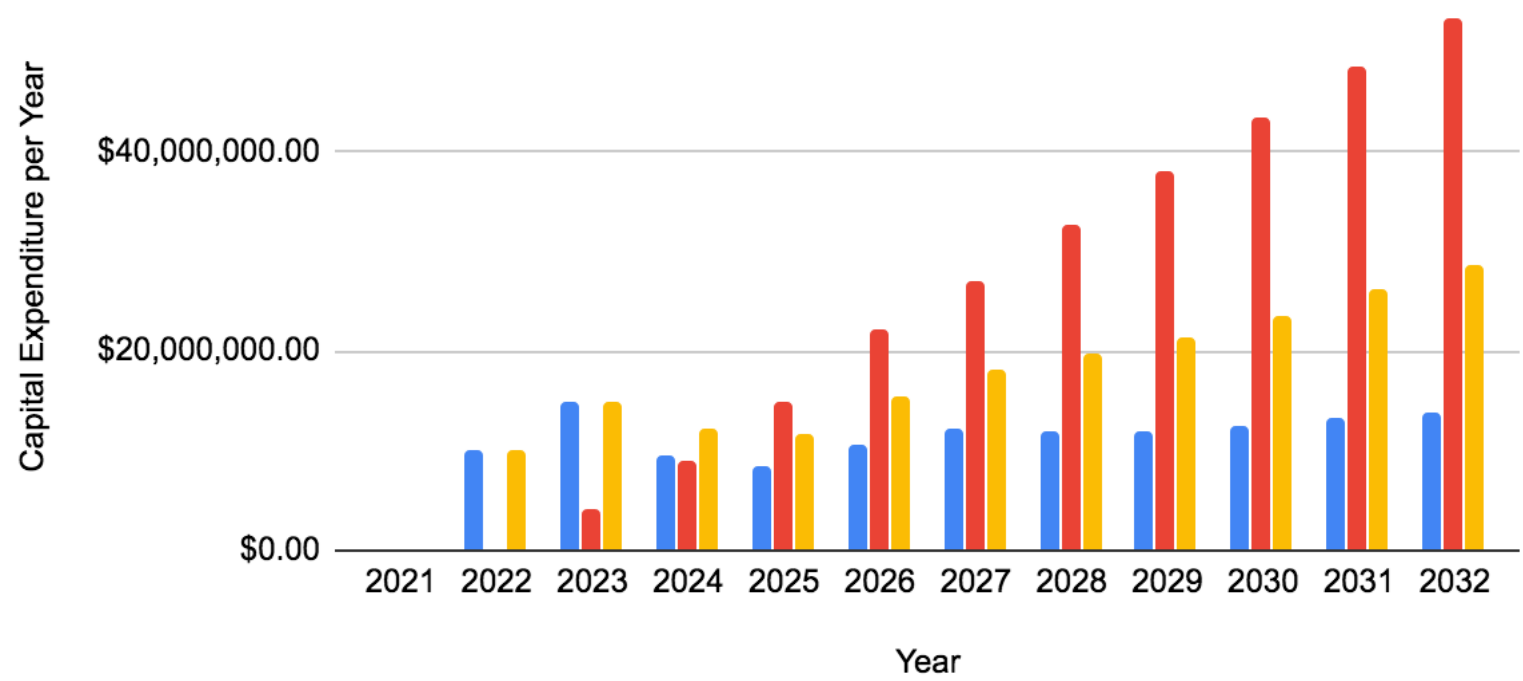

Figure D1. Capital Expenditures by Year for Three Recommendations: 1) REF Only, 2) Carbon Price Only, 3) REF + Carbon Price 


\section{APPENDIX D.9: Justification of Quadrupling Energy Managers}

Based on our conversations with Kevin Morgan, we estimate the need to quadruple the size of the current energy management team in order to provide enough expertise across campus to fully utilize the REF and achieve the desired emissions reductions. As of now, the OCS Energy Management Team is 11 members with a total annual cost to the University of $\$ 1.7$ million in salaries and benefits. 4 of these are regional energy managers (REMs). This team only handles General Fund buildings with an ECM budget of $\$ 1.2$ million. Extending services to auxiliary units on campus adds an additional 15.4 million square feet and 2.5 million MMBTUs to cover. Furthermore, since each REM will be responsible for achieving a greater emission reduction per year as compared to historic practice, the square footage assigned to each individual energy manager should be reduced, thus requiring a further expansion of the team. This will allow the REMs to become greater experts on their buildings and enable them to identify deeper reduction opportunities. Figure D2 shows how a quadrupling of the energy management team might look, allocated by square footage. We are recommending the existing team (Ex) +12 option, which both expands services to all of campus and reduces the average energy manager's assigned square footage.

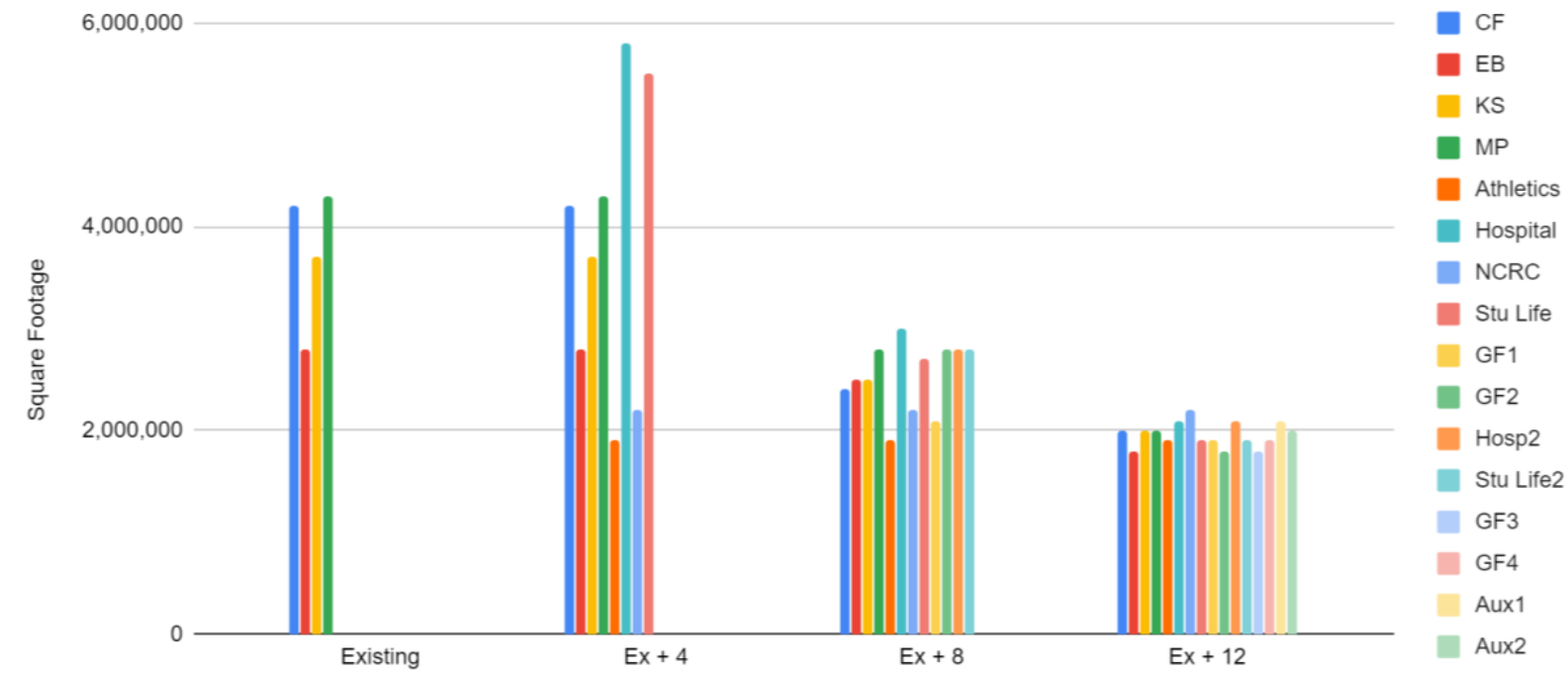

Figure D2. 


\section{APPENDIX E: Carbon Price}

\section{APPENDIX E.1: Emissions Reduction Calculations}

Calculations were done using the baseline consumption calculated for 2021, accounting for the PPA and CPP expansion. Elasticity estimates were taken from the Washington State Department of Commerce's Carbon Tax Assessment model and the U.S. Energy Administration Association. While our analysis endeavors to provide the best estimates possible with existing data, a couple key areas of uncertainty should be highlighted. First, the elasticity method for estimating emissions reductions from a carbon tax is a high-level approach based on the best available elasticity values in the literature but no U-M-specific data is available. Second, the GRITs method, using historic campus data, is an excellent approach as long as the GRITs projects remain representative of the project queue. However, inevitably as projects with the lowest COA are completed, the average COA will eventually increase. Similarly, data on the actual campus-wide opportunity for building energy use reduction is very sparse (though the SmithGroup's work will begin to address this) therefore we use a $25 \%$ estimate based on Engie's 10-year guarantee in their contract with Ohio State University. Beyond the $25 \%$ reduction, the COA escalates steeply at $30 \%$ per year to reflect the considerable uncertainty and challenges associated with deep building retrofits. The derivation of the COA is described in detail in Appendix B. Calculations used the following elasticity and stickiness data, where "stickiness" refers to the length of time it takes for long-run elasticity estimates to be fully achieved. Calculations were done as follows:

\begin{tabular}{|l|r|r|}
\hline \multirow{2}{*}{$\begin{array}{l}\text { Natural Gas } \\
\text { Electricity }\end{array}$} & -0.35 & Elasticity \\
\cline { 2 - 3 } LP Gas & -0.47 & 10 \\
\cline { 2 - 3 } Fuel Oil & -0.7 & 10 \\
\cline { 2 - 3 } & -0.37 & 10 \\
\hline
\end{tabular}

\section{Step One: Additional Cost $=$ Carbon Conversion Factor $\mathbf{x}$ Carbon Price}

Using energy intensity conversion factors we first found the additional cost of each energy source based on the respective carbon intensity.

\section{Step Two: Price Change = Additional Cost/Baseline Price}

A percent change in price was calculated for each energy source by dividing this additional cost by the baseline price from 2019.

\section{Step Three: Stickiness Factor $=$ Policy Year/Stickiness}

The relative year of the policy was then divided by the chosen stickiness factor for each energy source to create a ramp-in for consumption change.

\section{Step Four: Adjusted Long-Run Elasticity $=$ Stickiness Factor $x$ Elasticity}

The stickiness factor was then multiplied by the elasticity estimate to return an adjusted elasticity that accounts for a ramp-in period for each energy source. 
Step Five: Adjusted Consumption = Baseline Consumption $\times(1+$ Price Change $\mathbf{x}$ Adjusted Long-run Elasticity)

The adjusted consumption accounting for stickiness used the baseline consumption for 2021 to calculate how the price change will reduce consumption based on each energy source's elasticity estimate.

\section{Step Six: Adjusted Emissions = Adjusted Consumption x Conversion Factor}

Using conversion factors for each energy source the adjusted consumption was converted to a change in emissions. These conversion factors also accounted for the new DTE emissions factors for electricity and subtracted the avoided PPA emissions. 


\section{APPENDIX E.2: Budget Impact Calculations}

The table below presents estimates of the impact of carbon pricing on individual business units once the carbon price is fully phased in, along with a range of estimates of Direct Return funds. The table uses utilities consumption numbers from 2019, but weights them by anticipated emissions factors for 2021, in order to more accurately reflect the energy supply of the University that will apply in 2021 . The 2021 supply will reflect both the upgrade of the central power plant (CPP) and the large new power purchase agreement with DTE. As a result, the estimated emissions levels shown here are below the actual emissions levels for 2019. They may overstate future energy consumption after ECMs are implemented. (Of course, if business units construct new buildings then those would increase total consumption.) The 2019 consumption levels do not include expanded consumption of the additional steam that will be made available after the CPP upgrade is completed. Nevertheless, the key implication of the table is unlikely to change: carbon pricing will add less than $1 \%$ to the overall $U-M$ budget. The supporting data and calculations for this figure are available in the supplementary excel files under "Budget Impact by Unit."

\begin{tabular}{|c|c|c|c|c|c|c|}
\hline \multirow[t]{2}{*}{ BUDGETING UNIT } & \multirow[t]{2}{*}{ Total Emlsisons (MTCO2) } & \multirow{2}{*}{$\begin{array}{c}\text { Carbon Price Cost } \\
\$ 50 \\
\end{array}$} & \multirow[t]{2}{*}{ \% OF FY19 BUDGET } & \multicolumn{3}{|c|}{ Direct Return Amount e X\% } \\
\hline & & & & $30 \%$ & $40 \%$ & $50 \%$ \\
\hline A Alfred Taubman College of Architecture \& Urban Planning & 1,089 & $\$ 54,438$ & $0.25 \%$ & $\$ 16,331$ & $\$ 21,775$ & $\$ 27,219$ \\
\hline Penny W Stamps School of Art \& Design & 1,000 & $\$ 50,018$ & $0.36 \%$ & $\$ 15,005$ & $\$ 20,007$ & $\$ 25,009$ \\
\hline Stephen M Ross School of Business & 7,651 & $\$ 382,533$ & $0.33 \%$ & $\$ 114,760$ & $\$ 153,013$ & $\$ 191,266$ \\
\hline School of Dentistry & 7,620 & $\$ 381,019$ & $1.05 \%$ & $\$ 114,306$ & $\$ 152,408$ & $\$ 190,510$ \\
\hline School of Education & 2,692 & $\$ 134,603$ & $0.69 \%$ & $\$ 40,381$ & $\$ 53,841$ & $\$ 67,302$ \\
\hline College of Engineering & 20,510 & $\$ 1,025,517$ & $0.43 \%$ & $\$ 307,655$ & $\$ 410,207$ & $\$ 512,759$ \\
\hline School of Information & 517 & $\$ 25,853$ & $0.10 \%$ & $\$ 7,756$ & $\$ 10,341$ & $\$ 12,926$ \\
\hline School of Kinesiology & 622 & $\$ 31,095$ & $0.17 \%$ & $\$ 9,328$ & $\$ 12,438$ & $\$ 15,547$ \\
\hline Law School & 3,678 & $\$ 183,883$ & $0.37 \%$ & $\$ 55,165$ & $\$ 73,553$ & $\$ 91,941$ \\
\hline College of Literature Science and the Arts & 45,623 & $\$ 2,281,168$ & $0.54 \%$ & $\$ 684,350$ & $\$ 912,467$ & $\$ 1,140,584$ \\
\hline Medical School & 55,682 & $\$ 2,784,112$ & $2.98 \%$ & $\$ 835,234$ & $\$ 1,113,645$ & $\$ 1,392,056$ \\
\hline School of Music Theatre \& Dance & 4,370 & $\$ 218,510$ & $0.53 \%$ & $\$ 65,553$ & $\$ 87,404$ & $\$ 109,255$ \\
\hline School for Environment and Sustainability & 1,258 & $\$ 62,920$ & $0.35 \%$ & $\$ 18,876$ & $\$ 25,168$ & $\$ 31,460$ \\
\hline School of Nursing & 1,451 & $\$ 72,532$ & $0.32 \%$ & $\$ 21,760$ & $\$ 29,013$ & $\$ 36,266$ \\
\hline College of Pharmacy & 3,193 & $\$ 159,657$ & $0.90 \%$ & $\$ 47,897$ & $\$ 63,863$ & $\$ 79,828$ \\
\hline School of Public Health & 6,078 & $\$ 303,921$ & $0.71 \%$ & $\$ 91,176$ & $\$ 121,568$ & $\$ 151,960$ \\
\hline Gerald R Ford School of Public Policy & 689 & $\$ 34,470$ & $0.23 \%$ & $\$ 10,341$ & $\$ 13,788$ & $\$ 17,235$ \\
\hline School of Social Work & 3,240 & $\$ 162,006$ & $0.64 \%$ & $\$ 48,602$ & $\$ 64,803$ & $\$ 81,003$ \\
\hline Horace H Rackham School of Graduate Studies & 997 & $\$ 49,850$ & $0.48 \%$ & $\$ 14,955$ & $\$ 19,940$ & $\$ 24,925$ \\
\hline President & 752 & $\$ 37,578$ & $1.56 \%$ & $\$ 11,273$ & $\$ 15,031$ & $\$ 18,789$ \\
\hline Provost \& Executive Vice President for Academic Affairs & 28,564 & $\$ 1,428,193$ & $3.71 \%$ & $\$ 428,458$ & $\$ 571,277$ & $\$ 714,096$ \\
\hline Executive Vice President \& Chief Financial Officer & 52,935 & $\$ 2,646,760$ & $2.06 \%$ & $\$ 794,028$ & $\$ 1,058,704$ & $\$ 1,323,380$ \\
\hline Division of Public Safety \& Security & 342 & $\$ 17,100$ & $0.15 \%$ & $\$ 5,130$ & $\$ 6,840$ & $\$ 8,550$ \\
\hline Vice President for Communications & 283 & $\$ 14,162$ & $0.18 \%$ & $\$ 4,249$ & $\$ 5,665$ & $\$ 7,081$ \\
\hline Vice President \& General Counsel & 112 & $\$ 5,615$ & $0.12 \%$ & $\$ 1,684$ & $\$ 2,246$ & $\$ 2,807$ \\
\hline Vice President for Government Relations & 47 & $\$ 2,346$ & $0.10 \%$ & $\$ 704$ & $\$ 939$ & $\$ 1,173$ \\
\hline Vice President for Information Technology \& Chief Information Officer & 3,560 & $\$ 178,016$ & $0.32 \%$ & $\$ 53,405$ & $\$ 71,207$ & $\$ 89,008$ \\
\hline Vice President for Research Support Units & 1,298 & $\$ 64,925$ & $0.22 \%$ & $\$ 19,477$ & $\$ 25,970$ & $\$ 32,462$ \\
\hline Vice President \& Secretary of the University & 71 & $\$ 3,568$ & $0.41 \%$ & $\$ 1,070$ & $\$ 1,427$ & $\$ 1,784$ \\
\hline Vice President for Student Life & 40,572 & $\$ 2,028,613$ & $9.73 \%$ & $\$ 608,584$ & $\$ 811,445$ & $\$ 1,014,307$ \\
\hline General University Support & 35 & $\$ 1,733$ & $0.00 \%$ & $\$ 520$ & $\$ 693$ & $\$ 867$ \\
\hline Utilities & 707 & $\$ 35,367$ & $0.05 \%$ & $\$ 10,610$ & $\$ 14,147$ & $\$ 17,683$ \\
\hline North Campus Research Complex & 0 & \$o & $0.00 \%$ & \$o & So & so \\
\hline Michigan Medicine & 57,979 & $\$ 2,898,942$ & $0.06 \%$ & $\$ 869,683$ & $\$ 1,159,577$ & $\$ 1,449,471$ \\
\hline Intercollegiate Athletics & 15,650 & $\$ 782,518$ & $0.45 \%$ & $\$ 234,756$ & $\$ 313,007$ & $\$ 391,259$ \\
\hline Ann Arbor Total & 370,871 & $\$ 18,543,542$ & $0.66 \%$ & $\$ 5,563,063$ & $\$ 7,417,417$ & $\$ 9,271,771$ \\
\hline Dearborn Total & 22,740 & & & & & \\
\hline Flint Total & 27,740 & & & & & \\
\hline UM Total & 421,351 & $\$ 18,543,542$ & $0.66 \%$ & $\$ 5,563,063$ & $\$ 7,417,417$ & $\$ 9,271,771$ \\
\hline
\end{tabular}




\section{APPENDIX F: Details of Summary Table Calculations}

\section{Financial Savings Calculations}

To project U-M's savings from decreased utility costs, we converted the projected emissions reductions back into energy quantities by fuel source. From our calculations in Appendix C, calculating the emission reductions associated with a $25 \%$ reduction in BTU, we determined for every annual reduction in emissions what percentage of the reduction could be attributed to each source. The results are showing in Table F1.

\begin{tabular}{|l|c|}
\hline & $\begin{array}{c}\text { Average \% } \\
\text { Emissions Split }\end{array}$ \\
\hline Natural Gas & $57.45 \%$ \\
\hline Electricity & $42.55 \%$ \\
\hline
\end{tabular}

Table F1. Emissions Split

Redistributing emissions reductions accordingly, we converted $\mathrm{MTCO}_{2} \mathrm{e}$ back into their respective energy quantities used by utility billing (CCF for natural gas and kWh for electricity). Billing rates are taken from the U-M utilities website ${ }^{29}$ and reflect FY2020 rates. Beginning in FY2021, U-M reports an expected 3\% increase in utility costs due to the DTE PPA. We reflect this as a $3 \%$ increase in the price of Electricity-DTE, which is then held constant thereafter. Full details and supporting calculations for the summary tables are available in the supplementary excel files in the "Final Report Financial Model." 


\section{APPENDIX G: Data on Flint and Dearborn Campuses}

The data that are available regarding energy consumption and carbon emissions on the Flint and Dearborn campuses are much less detailed than those for the Ann Arbor campus. We thank Richard Hamilton for his assistance in gathering what data did exist. As Appendix E.2 shows, total 2019 emissions from the Dearborn campus were 22,740 $\mathrm{MTCO}_{2} \mathrm{e}$ and those from the Flint campus were $27,740 \mathrm{MTCO}_{2} \mathrm{e}$.

On the Dearborn campus, scope 1 emissions were 7,740 $\mathrm{MTCO}_{2} \mathrm{e}$ and scope 2 emissions (purchased electricity) were remaining 15,000 $\mathrm{MTCO}_{2} \mathrm{e}$. On the Flint campus, scope 1 emissions were 7,740 $\mathrm{MTCO}_{2} \mathrm{e}$ and scope 2 emissions (purchased electricity) were remaining $20,000 \mathrm{MTCO}_{2} \mathrm{e}$.

Individual emissions by building are not tracked on these two campuses, and utility bills are paid centrally. Thus, the sort of decentralized policies we propose for the Ann Arbor campus are not suitable for Flint and Dearborn, especially the imposition of a carbon price. However, the use of a dedicated REF by the central administration on each campus could be beneficial.

\section{Dearborn Seed Funding-\$2.2M}

\begin{tabular}{|c|c|c|c|c|c|c|c|c|c|c|c|c|c|}
\hline SNAPSHOT IMPACT & & 2021 & 2022 & 2023 & 2024 & 2025 & 2026 & 2027 & 2028 & 2029 & 2030 & 2031 & TOTAL \\
\hline \multicolumn{14}{|c|}{ REF ONLY } \\
\hline REF Seed Funding: $\$ 2.2 \mathrm{M}$ & Incremental Emissions Reduced & 0 & 1,224 & 298 & 366 & 453 & 559 & 546 & 500 & 539 & 568 & 582 & 5,637 \\
\hline Carbon Price: $\$ 0 / \mathrm{MTCO} 2$ & Cumulative Emissions Reduced & 0 & 1,224 & 1,523 & 1,889 & 2,342 & 2,901 & 3,448 & 3,948 & 4,486 & 5,055 & 5,637 & \\
\hline Emissions Reduction: $25 \%$ & Annual Costs & $\$ 2.2 \mathrm{M}$ & $\$ 0.0 \mathrm{M}$ & $\$ 0.0 \mathrm{M}$ & $\$ 0.0 \mathrm{M}$ & $\$ 0.0 \mathrm{M}$ & $\$ 0.0 \mathrm{M}$ & $\$ 0.0 \mathrm{M}$ & $\$ 0.0 \mathrm{M}$ & $\$ 0.0 \mathrm{M}$ & $\$ 0.0 \mathrm{M}$ & $\$ 0.0 \mathrm{M}$ & $\$ 2.2 \mathrm{M}$ \\
\hline \multirow[t]{2}{*}{ NPV: \$2.6M } & Annual Savings & $\$ 0.0 \mathrm{M}$ & $\$ 0.3 \mathrm{M}$ & $\$ 0.3 \mathrm{M}$ & $\$ 0.4 \mathrm{M}$ & $\$ 0.5 \mathrm{M}$ & $\$ 0.6 \mathrm{M}$ & $\$ 0.8 \mathrm{M}$ & $\$ 0.9 \mathrm{M}$ & $\$ 1.0 \mathrm{M}$ & $\$ 1.1 \mathrm{M}$ & $\$ 1.3 \mathrm{M}$ & $\$ 7.2 \mathrm{M}$ \\
\hline & \% Reduced from 2021 Baseline & $0.00 \%$ & $5.38 \%$ & $6.70 \%$ & $8.31 \%$ & $10.30 \%$ & $12.76 \%$ & $15.16 \%$ & $17.36 \%$ & $19.73 \%$ & $22.23 \%$ & $24.79 \%$ & $24.79 \%$ \\
\hline
\end{tabular}

\section{Flint Seed Funding-\$2.4 million}

\begin{tabular}{|c|c|c|c|c|c|c|c|c|c|c|c|c|c|}
\hline SNAPSHOT IMPACT & & 2021 & 2022 & 2023 & 2024 & 2025 & 2026 & 2027 & 2028 & 2029 & 2030 & 2031 & TOTAL \\
\hline \multicolumn{14}{|c|}{ REF ONLY } \\
\hline REF Seed Funding: $\$ 2.4 \mathrm{M}$ & Incremental Emissions Reduced & 0 & 1,490 & 363 & 446 & 551 & 681 & 665 & 608 & 656 & 692 & 709 & 6,862 \\
\hline Carbon Price: \$0/MTCO2 & Cumulative Emissions Reduced & 0 & 1,490 & 1,854 & 2,300 & 2,851 & 3,532 & 4,197 & 4,806 & 5,462 & 6,153 & 6,862 & \\
\hline Emissions Reduction: $25 \%$ & Annual Costs & $\$ 2.4 \mathrm{M}$ & $\$ 0.0 \mathrm{M}$ & $\$ 0.0 \mathrm{M}$ & $\$ 0.0 \mathrm{M}$ & $\$ 0.0 \mathrm{M}$ & $\$ 0.0 \mathrm{M}$ & $\$ 0.0 \mathrm{M}$ & $\$ 0.0 \mathrm{M}$ & $\$ 0.0 \mathrm{M}$ & $\$ 0.0 \mathrm{M}$ & $\$ 0.0 \mathrm{M}$ & $\$ 2.4 \mathrm{M}$ \\
\hline \multirow[t]{2}{*}{ NPV: \$3.3M } & Annual Savings & $\$ 0.0 \mathrm{M}$ & $\$ 0.3 \mathrm{M}$ & $\$ 0.4 \mathrm{M}$ & $\$ 0.5 \mathrm{M}$ & $\$ 0.6 \mathrm{M}$ & $\$ 0.8 \mathrm{M}$ & $\$ 0.9 \mathrm{M}$ & $\$ 1.1 \mathrm{M}$ & $\$ 1.2 \mathrm{M}$ & $\$ 1.4 \mathrm{M}$ & $\$ 1.5 \mathrm{M}$ & $\$ 8.7 \mathrm{M}$ \\
\hline & \% Reduced from 2021 Baseline & $0.00 \%$ & $5.37 \%$ & $6.68 \%$ & $8.29 \%$ & $10.28 \%$ & $12.73 \%$ & $15.13 \%$ & $17.32 \%$ & $19.69 \%$ & $22.18 \%$ & $24.74 \%$ & $24.74 \%$ \\
\hline
\end{tabular}




\section{APPENDIX H: Other Recommendations}

Although we dedicated the majority of our time to developing our priority recommendations, we did a surface-level investigation in four other areas where energy consumption policies and/or programs could be implemented: contracting, on-campus housing competitions, and off-campus housing.

\section{Contracting}

The PCCN should immediately recommend that U-M's Architecture, Engineering, and Construction department review their procurement and contracting process and make suggestions about how to incorporate energy-performance based procurement. Contract structure for large construction projects presents a valuable opportunity to further incorporate sustainability goals throughout University practices. Historically, construction contracts do not incorporate energy use intensity targets beyond applicable building codes. Moreover, financial incentives for construction and architectural firms are centered around minimizing first cost and delivery timeline with little to no relationship to long term building performance or efficiency. Implementing energy performance-based procurement practices can realign the contracting structure to prioritize energy performance throughout the design and construction process. Many thought leaders in the commercial building sector such as the Department of Energy and National Institute of Building Sciences have excellent resources on how to incorporate energyperformance into procurement. These links provide a starting point for learning how to leverage this powerful opportunity.

1. Department of Energy https://www1.eere.energy.gov/buildings/publications/pdfs/rsf/performance based how $t$ o guide.pdf

2. National Institute of Building Sciences https://newbuildings.org/sites/default/files/Performance Outcomes Summit Report 515.pdf

3. Minnesota Department of Commerce https://www.cards.commerce.state.mn.us/CARDS/security/search.do?documentld=\%7B 4DE4E430-400B-4ABB-B6E1-78D7D6AD4F7F\%7D

\section{Energy Reduction Competitions}

Energy reduction competitions, especially among college dormitories, are a common way universities strive to reduce their energy consumption. We looked into energy competitions at 10 schools and our main takeaway is that although these can help reduce energy consumption, because they are behavioral changes the most challenging aspect is to make them long-term. Competitions must be done frequently enough to sustain change but not so frequently that no new changes result from the efforts. Thus, while there is certainly value in pursuing these types of programs at U-M, the PCCN should not count on them to be permanent changes in the overall accounting of University emissions. That being said, there is a large educational and community awareness to these actions that should be considered.

\section{Programs investigated:}

Indiana University: https://sustainability.iupui.edu/engagement/energy-challenge/index.html 
University of California Campuses: https://hub.aashe.org/browse/presentation/22436/CoolCampus-Challenge-Engaging-Campuses-in-Carbon-Neutrality-to-Create-a-Culture-of-

Sustainability

University of Denver: https://www.du.edu/housing/sustainability/educational/index.html

Smith College: https://hub.aashe.org/browse/presentation/20357/Smith-College-House-

Sustainability-Challenge

Allegheny College: https://www-emerald-

com.proxy.lib.umich.edu/insight/content/doi/10.1108/IJSHE-08-2015-0144/full/pdf?title=energy-

challenges-isolating-results-due-to-behavior-change

St. Louis University:

https://hub.aashe.org/browse/presentation/16207/energy-maddness-a-residence-hall-energy-

competition

USC: https://hub.aashe.org/browse/publication/15309/What-goes-on-behind-closed-doors-Howcollege-dormitory-residents-change-to-save-energy-during-a-competition-based-energyreduction-intervention

UC Berkeley: https://hub.aashe.org/browse/presentation/10361/green-cup-the-greek-energysaving-competition

UNC: http://greengames.web.unc.edu/

\section{Off-Campus Housing}

Although the primary scope of our recommendation focuses on scopes 1 and 2 emissions related to building energy consumption, we believe it crucial for the University to consider scope 3 emissions from off-campus residences. This is a gap unfulfilled by any of the internal analysis teams at present. At U-M in $2019,69 \%$ of enrolled students $(48,090)$ live off-campus, ${ }^{30}$ many residing in the immediate vicinity of the University and others commuting to campus. College off-campus housing is notorious for being highly inefficient, the exception being newer residences that are only accessible to high-income students. One of the reasons for this is split incentives - neither the tenant nor landlord are incentivized to improve the energy efficiency of the residence. If landlords are the ones paying the utility bill, tenants have no incentive to modify their own behavior. That is often why most landlords require tenants to pay for utilities. However, this burdens the tenants with the cost of inefficiency. Since the landlord does not interact with this bill, they have no incentive to make upgrades to lower this cost. Furthermore, this does not affect their ability to rent because there is already a shortage of affordable housing and can attract renters no matter how run down and inefficient the unit is.

Additionally, even if the tenant is financially motivated to reduce their utility bill, there are time and legal barriers to doing so. Most students rent for one year at a time, occasionally renewing for second year. This short time provides little incentive to invest in efficiency because the payback period is longer than their stay. Even the most straightforward energy efficiency measure in homes-switching from incandescent bulbs to LED bulbs-have longer than a oneyear payback. ${ }^{31}$ Translate that to larger appliances such as refrigerators, and you are looking at $5+$ year paybacks even for 20 -year old models. ${ }^{32}$ No renter is going to make that investment if they are going to leave at the end of the year. Furthermore, since the renter does not legally own the property, they are often barred from executing upgrades. Laundry machines are a 
common example. Many properties still have coin-operated machines that are far from the most efficient models. Between the energy and water costs, and the coin-operated cost of doing a load of laundry, it is frequently cheaper for residents to buy their own machine. However, they are legally prohibited from doing so. In addition to basic appliances, one effective efficiency measure is installing a programmable thermostat. This allows tenants to implement a heating/cooling schedule aligned with the hours they are actually home and active. However, many landlords consider this an alteration to their property and prohibit it.

This is additionally an equity problem. Housing in Ann Arbor is already very expensive, one of the main reasons students choose to commute from farther cities. Utility bills are another added expense on top of this housing price and can blindside many renters. Especially if students are already living paycheck to paycheck, this can be the difference between taking on a third job and getting evicted. Thus, although U-M has a reputation for an affluent demographic, as diversity initiatives grow, U-M needs to provide more housing support for those with lower socioeconomic statuses. Aiding in off-campus efficiency measures is one way to provide such support.

Michigan has an opportunity to be a leader in higher education by becoming one of the first schools to make significant efforts in reducing the off-campus housing footprint. Two suggestions we have for the University are to partner with RentLab and assist local tenants in utilizing the Department of Energy SCORE program.

\section{RentLab ${ }^{33}$}

We were fortunate to meet with RentLab co-founders Jacqui Bauer and Matt Naud this spring and gain a deeper understanding of their organization and potential partnership with U-M. RentLab is a startup in the data analytics space aimed at bringing transparency to the rental housing process. They are developing a platform where renters can gain insights into the full cost of rental housing, including transportation and utilities, and are in the process of partnering with U.S. cities and universities to pilot this platform. With the help of current tenants and landlords, RentLab collects utility bills from the rental unit, scrubbed of any personal or confidential information. Over time, this presents a snapshot of typical utility costs for the unit throughout the year. Prospective tenants are able to browse this information online and see what the real total monthly and annual cost of the housing is. This will help renters make better informed decisions about what locations are most affordable and prevent tenants from becoming blindsided from extra, or even unaffordable, expenses. Signing for a slightly more expensive monthly rent could be a better option than cheaper rent with more expensive utilities-RentLab would allow renters to see this. Transparency will also create more competition among landlords, incentivizing for more energy efficiency upgrades in their units.

Right now, RentLab is partnering with the University of Missouri in Columbia and Northern Arizona University in Flagstaff to get their rental units on this platform. As Matt Naud was the first Environmental Coordinator for the City of Ann Arbor and a graduate alumnus of the University of Michigan, they have already reached out to try and form a partnership with U-M. 
However, U-M has yet to come on board. As part of its commitment to carbon neutrality, we strongly recommend U-M consider a partnership with RentLab.

\section{Home Energy Score Program ${ }^{34}$}

The Home Score Energy Program is run through the Department of Energy as a way to provide homeowners with "directly comparable and credible information about a home's energy usage." Assessors perform an energy audit on the home and give it a score from 1 to 10, 10 representing the most energy efficient homes in the United States. This program initially targeted the real estate market by creating a competitive metric for homeowners to compare before buying. However, this model can be adapted for rental housing and U-M has the opportunity to become a partner in this.

We spoke with Sarah Stoeckl, Program Manager in Campus Planning and Facilities Management within the University of Oregon Office of Sustainability. The University of Oregon has created a model where the University pays for select students to become trained Home Energy Score Assessors and, in partnership with their city and local utilities, provides free scores to local rental properties. This score is sent to both the tenant and landlord in addition to a list of recommended upgrades and behavioral changes to improve the score. Similar to RentLab, they hope to create a database of these energy scores in the future; however, they are running into some resistance from landlords about publicly releasing scores. In the first two years of the program, the University of Oregon assessed approximately 600 rental properties. While not all landlords made adjustments to their properties after the audit, some did rise to the challenge and made appropriate upgrades. The tenant-specific changes list help renters improve aspects that are actually within their control.

The University of Michigan could adopt a similar model to help reduce scope 3 emissions from off-campus housing. Furthermore, U-M students could also get real-world, nationally accredited experience in performing energy audits. This would not only allow the University to be a leader in creative solutions for carbon neutrality but would also continue its excellence in preparing graduates for the professional world. 


\section{APPENDIX I: INTERNAL AND EXTERNAL STAKEHOLDERS}

We have consulted with a number of external entities to gather information, but we have focused our stakeholder engagement efforts on internal stakeholders, primarily various business units around campus. The stakeholders with whom we have met include:

We have consulted with a number of external entities to gather information, but we have focused our stakeholder engagement efforts on internal stakeholders, primarily various business units around campus. The stakeholders with whom we have met include:

- U-M Office of Campus Sustainability

- U-M Provost office

- Clean Wolverines Report on a carbon price at U-M

- Clean Wolverine Report on Revolving Energy Funds at U-M

- U-M Energy Management for General Fund buildings

- Metrus Energy

- Leading the proxy pricing study in which U-M is participating; read his paper on carbon pricing in higher education institutions

- U-M faculty member, School for Environment and Sustainability

- U-M faculty member, School for Environment and Sustainability

- Faculty Lead, IAT Buildings Team

- U-M staff, NCRC/Med School Staff

- Director of Operations, U-M Life Sciences Institute

- U-M Athletics, Associate Athletic Director of Facility Operations

- U-M Flint, Facilities and Operations, Instrument and Controls Repair

- U-M Dearborn, Director of Energy \& Sustainability

- U-M Dearborn, Executive Director for Facilities

- U-M Student Life, Senior Director University Unions \& Auxiliary Services

- U-M Student Life, Director of Student Life Auxiliary Facilities \& Capital Projects

- Michigan Dining, Senior Director

- Michigan Medicine, Associate Director of Facility Planning and Operations

- Director of Sustainability at the University of Minnesota

- Energy and Sustainability Manager, Cal State Los Angeles

- Co-founders of RentLab

- Campus Planning and Facilities Management, University of Oregon Office of Sustainability

- Planet Blue Ambassador Program Coordinator

- Professor of Environmental Policy, author of the book Can We Price Carbon?

- CFO of Ross School of Business

- Sustainability and Energy Management, Facilities \& Energy Management at Stanford

- Energy Advisory Committee Chair, City of Montpelier, Vermont

- Campus Sustainability Manager at Weber State University

- Sustainability Manager at the University of Miami Florida 
APPENDIX J: REF Performance with Alternative Starting Funds and No Carbon Price

$\begin{array}{cccc}\begin{array}{c}\text { Seed Fund } \\ (\$ M)\end{array} & \begin{array}{c}\text { GHG Reduction } \\ (\%)\end{array} & \begin{array}{c}\text { 10-year } \\ \text { NPV }(\$ M)\end{array} \\ & & & \\ \$ & 10.00 & 11 \% & \$ 11.80 \\ \$ & 20.00 & 21 \% & \$ 21.80 \\ \$ & 30.00 & 30 \% & \$ 28.40 \\ \$ & 40.00 & 34 \% & \$ 30.60 \\ \$ & 50.00 & 38 \% & \$ 29.00 \\ \$ & 60.00 & 43 \% & \$ 27.40\end{array}$

Key Assumptions:

- Incorporating only returns over the period 2021-2031 so this understates NPV

- Reductions are relative to 2022 emissions after the PPA with DTE is signed

- Reductions beyond $25 \%$ are assumed to cost $30 \%$ more, which is why NPV increases slow down with growth of REF 


\section{APPENDIX K: TEAM BIOGRAPHIES}

\section{Faculty Lead}

Thomas P. Lyon holds the Dow Chair of Sustainable Science, Technology and Commerce at the University of Michigan, with appointments in both the Ross School of Business and the School of Environment and Sustainability. He is President of the Alliance for Research on Corporate Sustainability (ARCS) and has served as Director of the Erb Institute for Global Sustainable Enterprise and as Associate Director for Policy and Social Science at the U-M Energy Institute.

\section{Team Members}

Jessica Carlin is a rising senior pursuing a BA in Environment and a minor in Business Administration. During summer 2020, she worked as a product management intern for Equinix, where she gained experience that she can apply in future aspirations of becoming a Product Manager for sustainable consumer products. Jessica is looking forward to using the skills she has built in this research position as well as her coursework focusing on the intersection of environmental stewardship and corporate business practices in her upcoming career.

Lyanda Dudley is a College of Engineering master's student, who graduated in August 2020 with a MEng in Energy Systems Engineering from the Integrative Systems and Design Program. During summer 2020, she worked to complete her capstone project on net-zero energy retrofits and served as a renewable energy intern with McKinstry in Golden, Colorado. Lyanda hopes to actively use everything she has learned from her experience with this research team in her future work in the sustainable buildings sector.

Taylor Lind graduated with a BS in Economics and Program in the Environment and a Sustainability minor. During her time at U-M, she held executive roles for both the Residence Hall Association, where she led many initiatives in Housing and Dining sustainability, and Students for Clean Energy, where she organized a volunteer solar installation with the City of Ann Arbor. Taylor strives to support organizations and communities in creating and achieving sustainability goals in their operations. In the long run, Taylor would eventually like to go back to school for an MBA and implement large-scale sustainable change for a large corporation.

Larson Lovdal is a master's student in Mechanical Engineering focusing on the intersection of technology and finance to accelerate an equitable clean energy transition. While at Michigan, he will also pursue an MS in Sustainable Systems at the School of the Environment and Sustainability. Before coming to Michigan, he was an associate at the Stone House Group working on energy strategy and worked in residential construction in California and worked in renewables investment banking at CohnReznick Capital. Larson received his BA in Physics from Middlebury College.

Katarina Nehrkorn graduated in May 2020 with a BA in Economics with minors in the Environment and Business. During her time at the University of Michigan she participated in undergraduate research focusing on both politics and the environment. After graduation she will be working in Risk and Financial Advisory at Deloitte. She hopes to use this knowledge to better understand how policy can incentivize environmental sustainability in business. 


\section{Endnotes}

${ }^{1}$ Nordhaus, William D. 2017. "Revisiting the Social Cost of Carbon." Proceedings of the National Academy of Sciences 114, no. 7: 1518-1523.

2 Billion Dollar Green Challenge. Accessed February 2020. http://greenbillion.org/.

${ }^{3}$ The GRITS data include only capital costs and do not reflect labor costs required to formulate, evaluate, and monitor installation of ECMs. Our estimates of future ECM costs include an allocation of labor costs to try to provide a more complete picture of costs.

${ }^{4}$ University of Michigan. 2019. "U-M to Reduce Emissions through Renewable Energy Purchase from DTE Energy." Michigan News, April 9. https://news.umich.edu/u-m-to-reduce-emissions-throughrenewable-energy-purchase-from-dte-energy/.

${ }^{5}$ See Appendix D.2 for a full breakdown of units (schools, auxiliaries, non-revenue generating business).

6 IDEA Campus Energy. 2018. “Comprehensive Energy Management 'A New Model.” https://www.districtenergy.org/viewdocument/comprehensive-energy-management-a.

${ }^{7}$ See Appendix C for EUI versus GHG reduction goals.

8 "Carbon Pricing Connect." CDP Disclosure Insight Action. Accessed April 24, 2020. https://www.cdp.net/en/climate/carbon-pricing/carbon-pricing-connect; "Internal Carbon Pricing in Higher Education Toolkit." Second Nature. Accessed April 24, 2020. https://secondnature.org/climate-actionguidance/carbon-pricing/; World Bank Group. 2019. "State and Trends of Carbon Pricing 2019." Washington, DC: World Bank. () World Bank. https://openknowledge.worldbank.org/handle/10986/31755. License: CC BY 3.0 IGO.

${ }^{9}$ Nothstein, Greg. "Carbon Tax Assessment Model." Washington State Department of Commerce. Accessed April 24, 2020. https://www.commerce.wa.gov/growing-the-economy/energy/washington-stateenergy-office/carbon-tax/.

10 "Fuel Competition in Power Generation and Elasticities of Substitution." June 2012. US Energy Information Administration. https://www.eia.gov/analysis/studies/fuelelasticities/pdf/eia-fuelelasticities.pdf.

${ }^{11}$ Engie Ohio State Presentation. 2018.

https://www.districtenergy.org/HigherLogic/System/DownloadDocumentFile.ashx?DocumentFileKey=fce8 e5c2-941d-2d09-5a60-b451ad738c3f\&forceDialog=0.

12 See Appendix $B$ for derivation of the cost to reduce the annual flow of carbon emissions by one more ton of $\mathrm{CO}_{2} \mathrm{e}$.

${ }^{13}$ See Appendix $G$ for derivations.

14 IDEA Campus Energy. 2018. “Comprehensive Energy Management 'A New Model."” https://www.districtenergy.org/viewdocument/comprehensive-energy-management-a.

${ }^{15}$ See Appendix D.5 for a list of expedited project categories.

${ }^{16}$ Subject to re-evaluation. 
17 If paired with a carbon price (see combined recommendation), this rate can be lowered to $3.5 \%$.

${ }^{18}$ See Stage 5 for M\&V requirements. See Appendix D.6 for percentage breakdown.

${ }^{19} \mathrm{M} \& \mathrm{~V}$ describes a set of activities to quantify ECM energy savings in performance-based contracting.

20 Office of Energy Efficiency and Renewable Energy. 2020. "Measurement and Verification for Federal Energy Savings Performance Contracts." https://www.energy.gov/eere/femp/measurement-andverification-federal-energy-savings-performance-contracts.

21 "Reporting Units: Schools and Colleges." Office of the Provost, University of Michigan. Accessed February 2020. https://www.provost.umich.edu/units/schools and colleges.html.

22 "Reporting Units: Academic Affairs." Office of the Provost, University of Michigan. Accessed February 2020. https://www.provost.umich.edu/units/academic affairs.html.

${ }^{23}$ Time-sensitive projects can include but are not limited to improvement opportunities where construction is already underway, grant deadlines, and installation with an immediate maintenance effort.

24 "ECC Homepage-Committee Details." Accessed February 2020.

https://sites.google.com/umich.edu/ecc/committee-details?authuser=0.

251 mechanical, 1 electrical.

${ }^{26}$ Hernandez, Arvel. 2018. "GRITS Guide (Green Revolving Fund Mode)_GRITS."

https://www.gogrits.org/docs/grits-guide-for-green-revolving-funds/.

${ }^{27} \mathrm{GRF}$ is another name for REF.

${ }^{28}$ Electricity, steam, natural gas, etc.

29 "Utility Rates | F\&O Utilities." Accessed February 2020. https://utilities.fo.umich.edu/services/energyutilities/business-services/utility-rates/.

30 "University of Michigan—Ann Arbor Student Life." 2019. U.S. News \& World Report. https://www.usnews.com/best-colleges/university-of-michigan-ann-arbor-9092/student-life.

31 "LEDBenchmark—LED Lighting Saving Cost Calculator." 2012. http://www.ledbenchmark.com/LEDCalculator.html.

32 On replacing a $1993-2000$ s refrigerator with an electricity rate of $\$ 0.17 / \mathrm{kWh}$, see "ENERGY STAR Refrigerator Calculator | ENERGY STAR.” 2020.

https://www.energystar.gov/index.cfm?fuseaction=refrig.calculator\&which=4\&rate=0.17\&3aValue=0\&rcon fig=Top+Freezer\&screen=4\&manu=1993-2000\&tvol=19.0-

$21.4+$ Cubic+Feet\&model=\&submit. $x=133 \&$ submit. $y=13$.

33 “THE RENTLAB VISION | RentLab.” 2020. RentLab. https://www.rentlab.org/the-rentlab-vision.

34 "Home Energy Score." 2017. University of Oregon, Campus Planning \& Facilities Management. https://cpfm.uoregon.edu/score. 